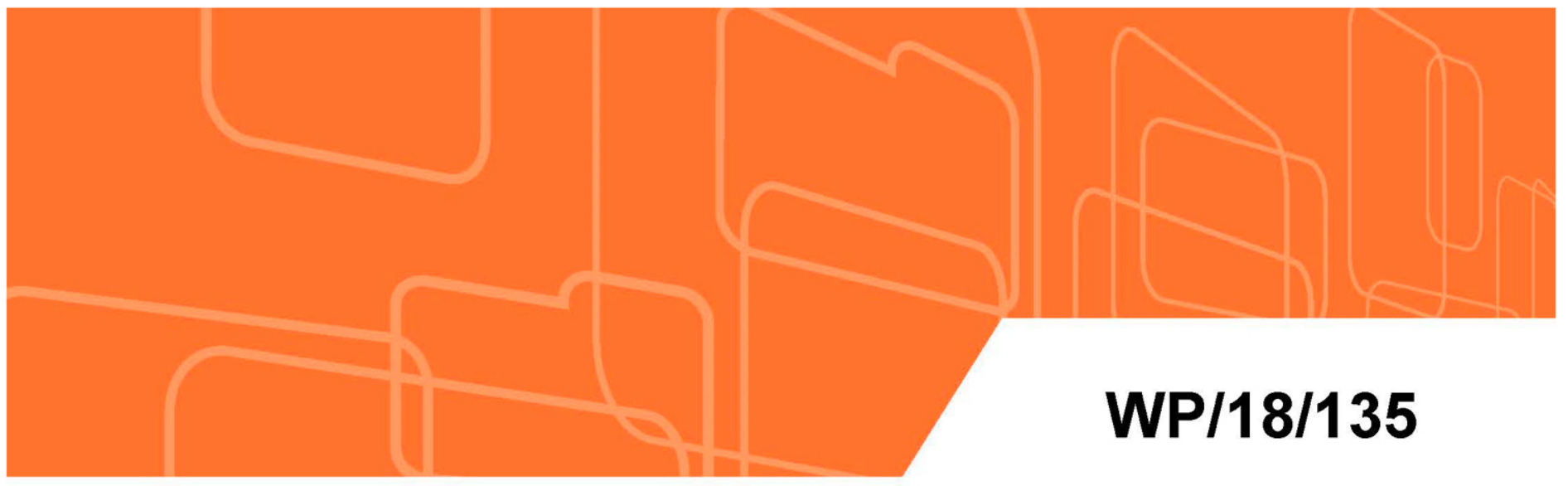

\title{
The Exposure to Routinization: Labor Market Implications for Developed and Developing Economies
}

by Mitali Das and Benjamin Hilgenstock

IMF Working Papers describe research in progress by the author(s) and are published to elicit comments and to encourage debate. The views expressed in IMF Working Papers are those of the author(s) and do not necessarily represent the views of the IMF, its Executive Board, or IMF management. 


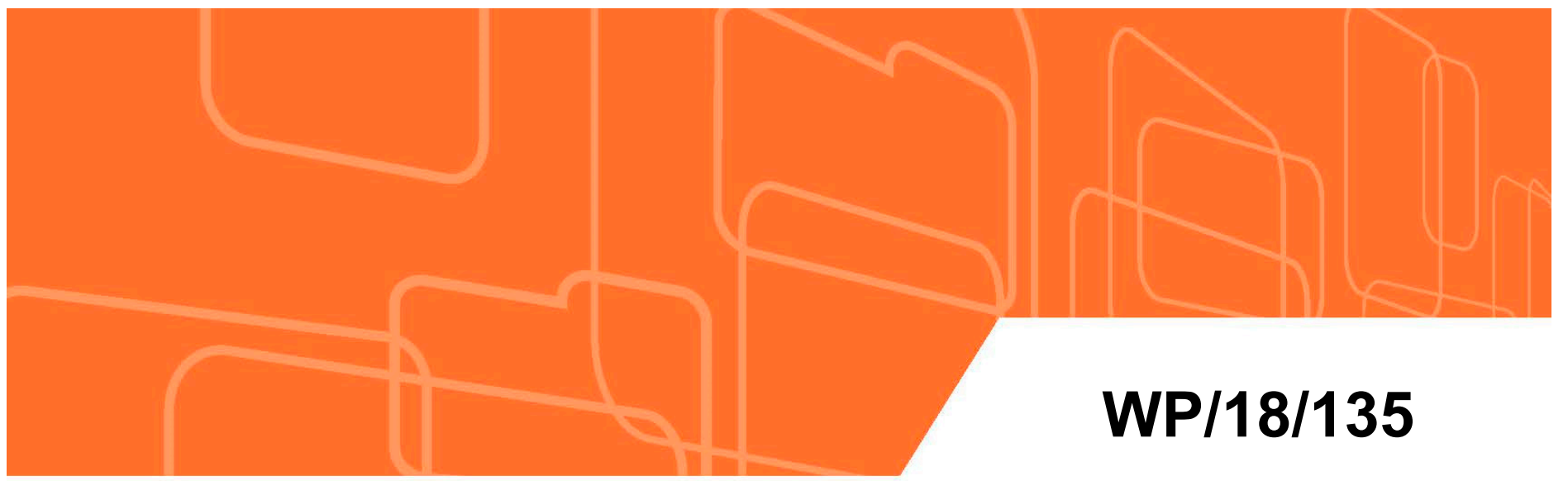

\section{IMF Working Paper}

\section{The Exposure to Routinization: Labor Market Implications for Developed and Developing Economies}

by Mitali Das and Benjamin Hilgenstock

IMF Working Papers describe research in progress by the author(s) and are published to elicit comments and to encourage debate. The views expressed in IMF Working Papers are those of the author(s) and do not necessarily represent the views of the IMF, its Executive Board, or IMF management. 


\title{
IMF Working Paper
}

\author{
Strategy, Policy and Review Department
}

The Exposure to Routinization:

\section{Labor Market Implications for Developed and Developing Economies ${ }^{1}$}

\author{
By Mitali Das and Benjamin Hilgenstock \\ Authorized for distribution by Martin D. Kaufman
}

June 2018

IMF Working Papers describe research in progress by the author(s) and are published to elicit comments and to encourage debate. The views expressed in IMF Working Papers are those of the author(s) and do not necessarily represent the views of the IMF, its Executive Board, or IMF management.

\begin{abstract}
Evidence that the automation of routine tasks has contributed to the polarization of labor markets has been documented for many developed economies, but little is known about its incidence in developing economies. We propose a measure of the exposure to routinization - that is, the risk of the displacement of labor by information technology - and assemble several facts that link the exposure to routinization with the prospects of polarization. Drawing on exposures for about 85 countries since 1990, we establish that: (1) developing economies are significantly less exposed to routinization than their developed counterparts; (2) the initial exposure to routinization is a strong predictor of the long-run exposure; and (3) among countries with high initial exposures to routinization, polarization dynamics have been strong and subsequent exposures have fallen; while among those with low initial exposure, the globalization of trade and structural transformation have prevailed and routine exposures have risen. Although we find little evidence of polarization in developing countries thus far, with rapidly rising exposures to routinization, the risks of future labor market polarization have escalated with potentially significant consequences for productivity, growth and distribution.
\end{abstract}

JEL Classification Numbers: E0, F16, J0, J21, O33

Keywords: $\quad$ Polarization, routine occupations, automation, structural transformation, information technology, globalization, inequality

Authors’ email address: $\quad$ mdas@imf.org, bhilgenstock@imf.org

${ }^{1}$ We thank Oya Celasun, Jihad Dagher, Mai Dao, Romain Duval, Gian Maria Milesi-Ferretti, Hao Jiang, Zsoka Koczan, Mary Hallward-Driemeier, Ryo Kambayashi, Weicheng Lian, Bill Mahoney, and Maury Obstfeld for their helpful comments. We thank Anna Salomon for discussions about the data, and seminar participants at the Swiss National Bank, the OECD, the WTO, the ILO, the Central Bank of Russia, the panel on Robots, AI and the Future of Work at the Institute of International Finance, and the G20 panel on the Future of Work in Bariloche Argentina for useful feedback. 


\section{CONTENTS}

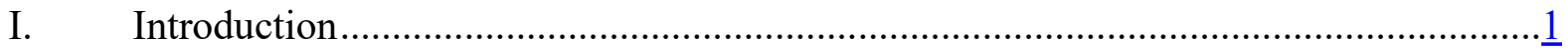

II. Exposure to Routinization: Aggregate Measures and Stylized Facts …...................... $\underline{8}$

III. Polarization in Developed and Developing Economies: Drivers and Mechanisms .... 19

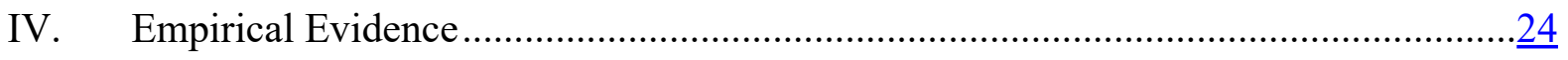

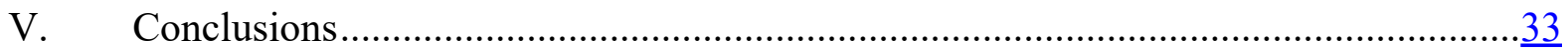

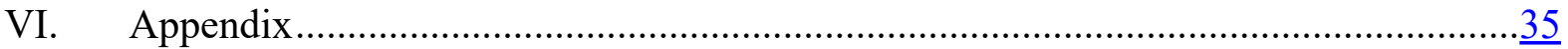

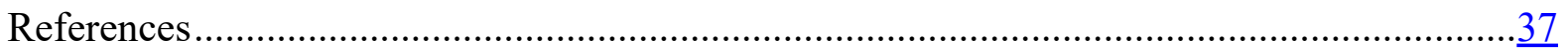

FIGURES

Figure 1. Aggregate Routinization Scores Across Occupations ....................................... 12

Figure 2. Distribution of Routine Exposure Across Industries........................................... 14

Figure 3. Evolution of Routine Exposure Across Country Groups …................................. 16

Figure 4. Initial Routine Exposure, Income Levels, and Subsequent Exposure.................... 18

Figure 5. Relative Price of Investment Goods in Developed and Developing Economies .... 21

Figure 6. Routine Scores of 1-Digit Occupations and Employment Shares....................... 22

Figure 7. Global Value Chain Participation and Change in Routine Exposure.................... 23

Figure 8. Initial Routine Exposure and Changes in Occupational Employment Shares ........ 29

\section{TABLES}

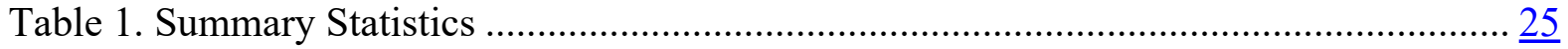

Table 2. Determinants of Long-Run Changes in Routine Exposure ................................ 27

Table 3. Initial Routine Exposure and Changes in Occupational Employment Shares.......... $\underline{28}$

Table 4. Determinants of Long-Run Changes in Occupational Employment Shares............ $\underline{32}$

Table A1. Economies and Time Coverage (as of 2018) .............................................. $\underline{36}$ 


\section{INTRODUCTION}

Concerns about the economic dislocation of workers are widespread in developed economies, and much of the recent discourse has focused on polarization of the labor market. Labor market polarization is the phenomenon of rising wages and higher employment of high- and low-skill labor relative to those in the middle of the skill distribution, which has come to be known as "hollowing out" of the middle (Autor, Katz and Kearney 2006; Goos and Manning 2007; Autor and Dorn 2013; Goos, Manning and Salomon 2014; Beaudry, Green and Sand 2016). The leading explanation for polarization is "routinization"- the hypothesis that middle-skilled jobs consist of routine tasks which follow a precise set of procedures easily automated by information and computer technology (ICT), thus displacing middle-skilled labor, whereas tasks performed by high-skilled labor are complementary to ICT and those performed by low-skilled labor largely neutral.

Evidence that routinization has contributed to labor market polarization has been documented in many developed economies, including the United States, Japan and sixteen European economies (Spitz-Oener 2006; Autor and Dorn 2013; Michaels, Natraj and Van Reenen 2013; Goos et. al. 2014; Ikenaga and Kamibayashi 2016). To date, however, much less is known about the incidence of routinization in developing economies, and whether the worldwide diffusion of advances in information technology has, or will, affect the structure of employment or wages, or result in polarizing their labor markets.

Our paper makes three contributions to this literature. First, we document the exposure to routinization in a large number of economies. By "exposure to routinization" we mean quantifying the extent to which jobs are at risk of being automated by ICT capital. Equivalently, the exposures are a measure of the propensity to adopt labor-displacing information technology. To this end, we propose a new, consistent and comparable measure of the exposure to routinization across countries, industries, and over time.

Second, we present stylized facts about the exposures to routinization, uncovering systematic differences between developing and developed economies which, to our knowledge, are new to the literature. A key finding is that the initial exposure to routinization contains important signals about long-run shifts in the occupational distribution of employment, and thus the prospects for polarization. These signals vary across economies at different stages of development reflecting, among other things, relative factor prices, the 
structure of production and the lags in technological adoption. As the exposures in an initial period are exogenous to subsequent shocks, the cross-country heterogeneity of exposures can provide important exogenous variation in assessing the long-run causal impact of the exposure to routinization on a range of macroeconomic outcomes. ${ }^{2}$

Third, we identify the drivers of the change in exposures to routinization over the last quarter century, empirically disentangling the roles of shifts in skill supply, the decline in the price of capital goods, structural transformation, and the globalization of trade. The evidence indicates that drivers differ fundamentally between developed and developing economies. Finally, we consider how the initial exposures are linked to long-run changes in sectoral employment and wages, and what they may imply for the future of labor markets in developing economies.

The measures we propose begin with a set of ordinal scores in Autor and Dorn (2013) which assign to all 3-digit census occupations a score reflecting its routine-task intensity, i.e., its likelihood of automation by information technology. By weighting scores with the corresponding employment share, the measure reflects how intensive a country is in the labor input of routine tasks and thus, the extent to which jobs are exposed to the risk of being substituted by computerization. As employment shares change over time, the measure is time-varying and sheds light on dynamics of exposures as well.

Drawing on national population censuses, labor force surveys and other sources, we construct exposures to routinization for 160 countries at annual, biennial, quinquennial or, most frequently, decennial frequency between 1960 and 2015. Routine exposures for fourteen 2-digit industries are constructed analogously. Our dataset covers 116 developing economies and 38 developed economies. ${ }^{3}$

The exposures to routinization contain several new stylized facts. First, we document that jobs in developing economies are significantly less exposed to automation than

\footnotetext{
${ }^{2}$ We originally constructed the exposures to quantify the differential impact of initial exposures on the labor share of income; see Box 3.3.3 in IMF (2017) and Dao, Das, Koczan and Lian (2017). These exposures have recently been used to analyze the trends in labor force participation (IMF 2018A) and the factors affecting youth employment (IMF 2018B).

${ }^{3}$ We symmetrically construct measures of measures of exposure to offshorability using scores in Blinder and Krueger (2013), which are described in an online appendix. These are not the focus of this paper.
} 
developed economies, and remain less exposed for the quarter century between 1990 and 2015. This is consistent with the widely-held notion that production is less capital-intensive in developing countries - potentially reflecting the low relative price of labor to capital (Hsieh and Klenow 2007; Eden and Gaggl 2014) — and that employment concentrates in manual, in-person tasks, such as low-skilled services, which are naturally indisposed to automation (Dao et. al 2017). Indeed, Dao et. al. estimate the aggregate elasticity of substitution between capital and labor to be lower than one in developing economies.

Second, the initial exposure to routinization is embedded with signals about the longrun shifts in the structure of employment and thus, the prospects of polarization. But there is a sharp asymmetry by the level of exposure. Among countries which were heavily exposed to routinization to start with, the higher was the initial exposure, the lower was the subsequent exposure. But among countries that had initially low exposures to routinization, the higher was the initial exposure, the lower was the subsequent rise in exposure. We find that this asymmetry reflects polarization forces in the former, but structural transformation and globalization in the latter. As a forward-looking indicator, this embeds the initial exposure to routinization with predictive power for future labor market developments.

Finally, we show a systematic convergence of routine exposures between developing and developed economies, resulting from falling exposures in developed economies but rising exposures in developing economies. Falling exposures in developed economies are to be expected - they are an immediate consequence of polarization, which has reduced the share of middle-skilled workers most exposed to displacement by ICT, and thus lowered subsequent exposure for the marginal worker.

Rising exposures in developing economies are prima facie evidence that automation has not displaced labor on any macro-significant scale, suggesting no evidence of polarization. Recently, however, conflicting views have emerged on whether these economies may be beginning to see incipient polarization. Some view falling middle-skilled employment shares in a few developing countries as evidence that polarization is underway (see World Bank (2016) and Reijnders and de Vries 2017). However, by assuming that broad groups of "middle-skilled" occupations are routine-intensive, their approach disregards the heterogeneity of routine intensity within occupations, potentially overstating the decline in 
routine-intensive employment; see Section 2. Furthermore, their conclusions are mutually contradictory for important cases such as China, India and Poland.

Our finding of rising routine exposures is consistent with Maloney and Molina (2016) who find no evidence of polarization in developing countries. To rigorously test this premise, however, we nevertheless consider that polarization may be underway, but offset by stronger forces. In particular, the employment shifts implied by rising exposures are consistent with the ongoing structural transformation of these economies, a provocative explanation that has emerged as an alternative to routinization in explaining the observed polarization in developed countries; see Baranyi and Siegel (2018) and Herrendorf et. al. (2014). We explore whether structural transformation lies behind the rising exposures in developing economies, and find strong empirical support for this hypothesis. ${ }^{4}$

The widespread incidence of polarization in developed countries has led to a popular discourse that underlying forces are likely to be universal. Several authors have identified technological advances as the predominant force. ${ }^{5}$ The argument is that both the rapid rise in the productivity of ICT and the steep decline in its real costs has presented firms with powerful incentives to automate middle-skilled jobs. While mid-skilled labor has been displaced to low-skilled jobs, the skill-bias of ICT has ratcheted up the demand for highskilled labor, leading to the observed growth in the employment shares of high- and lowskilled labor. Recently, Dao et. al. (2017) have highlighted that the accelerated decline in the relative price of investment is a developed economy phenomenon that is largely absent in developing countries. Furthermore, they argue that the scope for labor displacement in developing economies is limited given the low elasticity of factor substitution. A key conclusion of our paper is that the limited evidence of polarization in developing economies rests, to some degree, on both these factors.

\footnotetext{
${ }^{4}$ As routine tasks are concentrated in manufacturing, the increase in routine exposures in developing economies suggests an expansion of the industrial base and thus, evidence against premature deindustrialization (Rodrik 2016). Our result however, masks substantial heterogeneity across developing economies, as the exposures are ound to have risen in most Asian economies, Developing Europe and many low-income economies but remained almost unchanged in Latin America, which is not inconsistent with Rodrik's findings.

${ }^{5}$ See, for example, Katz and Murphy 1992; Levy and Murnane 1996; Card and DiNardo 2006; Autor et. al. 2006; Goos and Manning 2007; Firpo, Fortin and Lemieux 2011; Autor and Dorn 2013; Goos, Manning and Salomon 2015; Beaudry, Green and Sand 2016; and references within.
} 
The remainder of this paper is organized as follows. In Section 2, we describe the construction of the exposures to routinization and present stylized facts about these measures. Section 3 discusses the drivers and mechanisms which lie behind polarization in developed economies and assess whether these factors may act differently, or possibly not operate at all, in developing economies. In Section 4, we present an empirical analysis of the drivers of the change in routine exposures, occupational employment shares and wages emphasizing the differences between developed and developing economies. Section 5 concludes.

\section{Exposure to Routinization: Aggregate Measures And Stylized Facts Routine Tasks and the ICT Revolution}

The real cost of computing power is estimated to have fallen at a staggering rate of more than 50 percent annually between 1969 and 2005 (Nordhaus 2007). A fundamental insight about the implications of this technological revolution—on the nature of tasks, distribution of occupations and patterns of international trade - began with the characterization of tasks most likely to be affected by the surge in computing power as routine (or "codifiable") tasks in Autor, Levy and Murnane (2003).

As defined by Autor et. al., routine tasks “....require methodical repetition of an unwavering procedure...exhaustively specified with programmed instructions and performed by machines". Routine tasks thus concentrate in middle-skilled job such as assembly line work and clerical work whose tasks can be codified and performed by computers. At the other end of the spectrum, the flexibility and inter-personal skills required in many lowskilled services - food services, child care - do not follow precise procedures and are thus difficult to automate (Autor and Dorn 2013). Also non-routine are the complex, problemsolving tasks of high-skilled labor such as scientists, although unlike their low-skilled service counterparts, their tasks are complementary to computer capital (see e.g. Beaudry et. al 2016).

While an influential body of work has identified the automation of routine tasks as the predominant cause of polarization in developed economies, the magnitudes of dislocations vary significantly. For example, Goos et. al. (2015) estimate that between 1993 and 2006, the share of middle-skilled jobs remained unchanged in Portugal, but fell by about 5 percentage points in the Netherlands, and 15 percentage points in Austria. This suggests that if 
routinization lies behind polarization, routine exposures must vary across countries, or countries with comparable exposures must automate at different rates idiosyncratically, or both. Empirically assessing these considerations requires a consistent and comparable measure of routinization across industries, countries, and over time. The construction of these measures is described next. ${ }^{6}$

\section{Aggregate Metrics of the Exposure to Routinization}

Our metrics have at their base a set of scores from Autor and Dorn (2013) which score the "routine task intensity" (RTI), or how intensive an occupation is in routine tasks, for 330 occupations at the 3-digit census level. Autor and Dorn assign scores to reflect the routine, abstract and manual task content of each occupation in the U.S. Department of Labor's Dictionary of Occupational Titles (DOT). Using the DOT's description, Autor and Dorn define the routine score:

$$
R T I_{k}=\ln \left(T_{k}^{R}\right)-\ln \left(T_{k}^{M}\right)-\ln \left(T_{k}^{A}\right)
$$

where $T_{k}^{R}, T_{k}^{M}$, and $T_{k}^{A}$ respectively represent the routine, manual, and abstract task inputs in occupation $k$, each ranging from zero to ten. The scores contain no information other than the ordinal position of occupations in increasing order of routinizability. Thus, on the extreme left tail of this scale are occupations with the most non-routine tasks: farmers, firefighters, and kindergarten teachers; on the right end of the scale, those with the most routine tasks: proofreaders, cashiers, and office clerks.

An important assumption we make in constructing the exposures is that the intrinsic routinizability of a task (i.e. the qualities that inherently dispose a task to be automated by ICT), RTI, is fixed across industries, countries and over time. What this assumption entails is that tasks performed by, e.g., a babysitter, present inherent challenges to being automated, while those performed by an assembly line worker are inherently automatable, regardless of which industry or country or when they are performed. The assumed intrinsic routinzability

\footnotetext{
${ }^{6}$ These measures can be extended periodically using updated information on employment. For the majority of countries, the most comprehensive updates are in 5- or 10-year intervals in conjunction the national censuses.
}

(continued...) 
of a task is distinct from whether the task is actually automated, which may well vary across countries and over time. The assumption we make is only about the innate propensity of a task to be automated by ICT.

A first step is harmonizing the classification of employment across countries, industries and time. We assemble data on occupation shares from national censuses, labor force surveys, and multilateral organizations. ${ }^{8}$ These sources record employment using many different classification systems, in part because they originate with different vintages of the UN's international standard classifications of occupations (ISCO) prevailing when the data are recorded. Data sources also vary in the level of aggregation at which they report employment (even within the same ISCO).

These features dictate how we can feasibly construct the exposures so that they are consistently defined across units and over time. First, all data are harmonized so they can be mapped into a single classification system. As more than three-fourths of our sources record employment affiliations using the 1988 ISCO (henceforth ISCO-88), we harmonize the data by reclassifying all systems other than ISCO-88, using official crosswalks where available, to map them into ISCO-88. Many censuses and labor surveys use the one-digit level of aggregation level in assigning occupation categories. This guides our choice of constructing the exposures to routinization at the 1-digit occupation level.

\footnotetext{
${ }^{7}$ The assumption is not without limitations. Tasks that were initially thought to be inherently non-routine, reflecting the available technology of the time, could over very long periods of time become routine. An example is navigating a taxi or bus, which were previously viewed as among the least routine occupations, but have become increasingly routine as autonomous-driving technologies have emerged. We posit that our assumption is generally palatable over reasonably short lengths of time, such as the quarter century 1990-2015 we consider in this paper. We thank Maury Obstfeld for this observation.

${ }^{8}$ Our sources include both public and proprietary data from the Integrated Public Use Microdata Series (IPUMS), European Union Labor Force Survey (EULFS), the United Nations statistical databases, the ILO, and several national authorities' data. Routine exposures are constructed for all years in which a national census or labor force survey was conducted. Between 1960 and 2015, this yields time-varying routine exposures for 160 countries at the aggregate (i.e. country) level and 126 countries at the industry level, at either annual, biannual, quinquennial or decennial frequencies. Exposures at industry levels are available for a slightly smaller subset since not all censuses, surveys and national statistics offices record the industry affiliation of the employed. In general, exposures are available at annual frequency for many advanced economies and some developing economies after 1990, while the frequencies are lower for economies prior to 1990.
}

(continued...) 
The next step is averaging the routine scores of all 3-digit occupations within each 1digit ISCO-88 category, to yield aggregate routinization scores for the nine 1-digit occupations:

$$
R T I_{l}=\frac{\sum_{k} R T I_{k}}{k} \quad(l=1, \ldots, 9)
$$

where $l$ represents the one-digit ISCO-88 occupation category and $k$ are the number of 3-digit occupations within each ISCO- 88 category. 9,10 These scores are standardized to have mean zero and standard deviation one, implying that occupations with positive scores are relatively more routine-intensive, and those with negative scores less so.

The distribution of the aggregated scores, along with the underlying 3-digit scores, are shown in the box-whisker plots in Figure 1. Note that the dots, representing the aggregated scores, do not necessarily lie in the center of the whiskers. This is because the 3digit routine scores are not necessarily uniformly distributed within the 1-digit category they constitute, and may well be skewed toward occupations with either high or low routine scores.

Two remarks on the aggregated scores are in order. First, with regards to the ranking: the group with the highest aggregated routine score is "clerical workers", which includes jobs such as bank tellers and mail carriers. They are followed by "machine operators" (including among them railroad operators) and "craft workers" (e.g., bakers and butchers). The least routine categories are "skilled agricultural, forestry and fishery workers", followed by "managers" and "professionals" who includes a wide range of jobs from teachers and lawyers, to scientists and physicians.

\footnotetext{
${ }^{9}$ The number of occupations, $k$, in one-digit ISCO-88 ranges from a low of 7 (among agricultural workers) to 152 (among professionals), but range considerably among the others, e.g., there are 46 sub categories of occupations among clerical workers and 78 among machine operators.

${ }^{10}$ We have constructed an alternative set of exposures using 3-digit level disaggregated occupation data for the subset of countries and industries where employment affiliations are available. These are not used to describe the stylized facts in this paper. We have also checked the robustness of our method by using medians and winsorized means in place of averages.
} 


\section{Figure 1. Aggregate Routinization Scores Across Occupations}

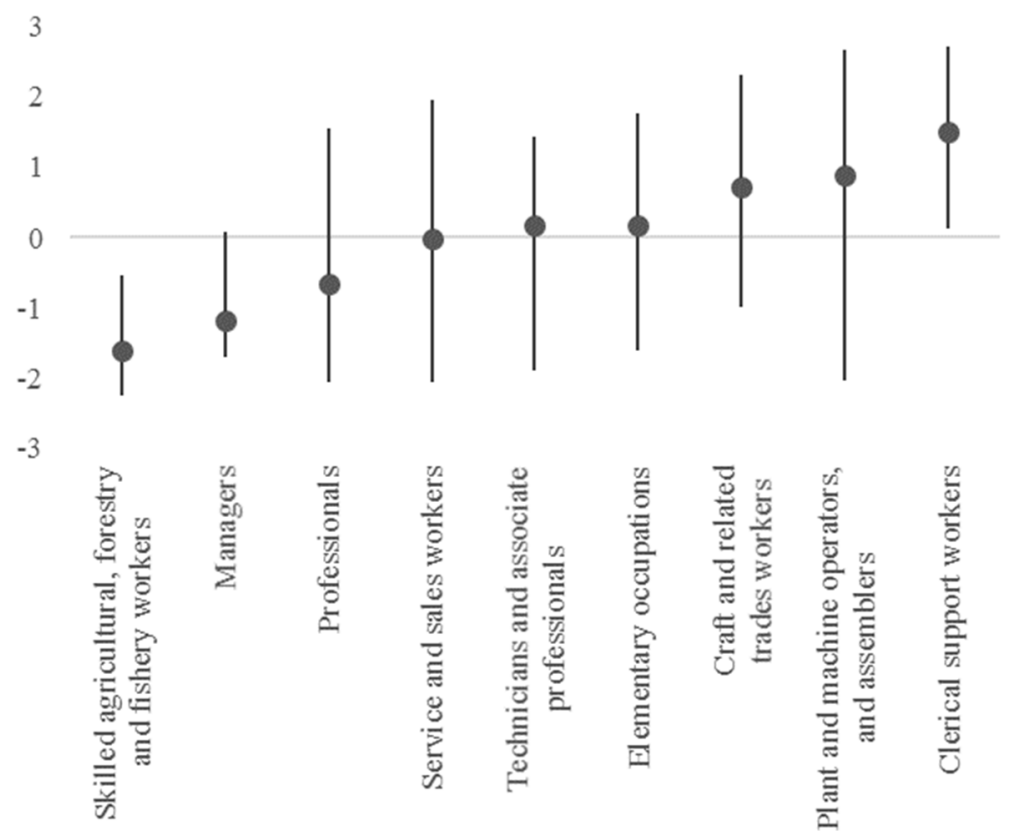

Sources: Autor and Dorn (2013), databases listed in footnote 8, and authors' calculations.

Second, routine scores vary significantly within occupation groups. Even when the average score of a 1-digit occupation is higher than another's, many of its constituent 3-digit occupations have lower scores than those which constitute the latter. For example, "Professionals" have lower average scores than "machine operators", but some professional occupations such as pharmacists have higher scores than certain "machine operators" such as railroad operators. This highlights that assigning, e.g., all machine operators, clerical workers and craft workers as middle-skilled labor "intensive in routine tasks" (see, e.g., World Bank 2016; and Reijnders and de Vries 2017), may overstates the number of routine workers genuinely displaced by automation.

Finally, we construct the routine exposures by weighting $R T I_{l}$ with corresponding employment shares. For occupation category $l$, industry $j$ and country $i$ at time $t$, industryand country-level exposures to routinization are constructed as respectively:

$$
R T I_{j i t}=\sum_{l} \omega_{l j i t} \times R T I_{l}, \quad R T I_{i t}=\sum_{l} \omega_{l i t} \times R T I_{l}
$$

where $\omega_{l j i t}$ and $\omega_{\text {lit }}$ are respectively occupation l's share of employment in industry $j$, country $i$ at $t$; and occupation $l$ 's share of employment in country $i$ at $t$. 
The exposures are unit free. Note that all industries are constituted by a range of occupations with varied routine intensities, but some industries, like manufacturing, are inherently disposed to consist of more codifiable tasks than others such as agriculture. The diversity in the share of occupations with high routine intensity across industries drives the inter-industry differences in routine exposures, while the diversity in the share of industries with high routine-exposures drive the inter-country variation.

A point we stress is that it the exposures to routinization do not measure the probability of automation, which would depend inter alia on the evolution of relative factor costs. This differentiates our measure from the probabilistic measure in Frey and Osbourne (2017).

\section{Stylized Facts}

The exposures to routinization contain a wealth of information. At a given point in time, their diversity reveals how widely the routine-intensity of the labor force varies across countries or industries, and thus how varied is their susceptibility to automation by information technology. Over time, they reveal tremendous variation in the rates at which routine-intensive labor has been substituted by technology, but they also uncover systematic similarities for countries by stage of development. We turn to these stylized facts next.

\section{A. In both developed and developing economies, exposures to routinization across industries vary considerably.}

Figure 2 presents the distribution of routinization exposures across industries. Panel A shows the "initial" exposure, which we measure as the earliest available observation in 199095 while panel B shows the "subsequent" exposure, measured at the last available observation in 2010-15. Both panels also show the average routine exposures for each industry, separately for developed and developing economies. ${ }^{11}$ The width of each boxwhisker plot represents the range of routine exposures across all economies.

\footnotetext{
${ }^{11}$ These are weighted averages, with weights given by value added, and are calculated separately for developed and developed economies. For example, for developed economies the weights are the share of an industry's value added in the total value added of that industry across all developed economies. The same weighting scheme is used for developing economies.
} 
The key findings are as follows: reflecting the manual, on-site nature of tasks, the agriculture industry has the lowest exposure to routinization in both time periods. This is consistent with Figure 1, which shows that the occupation "skilled agricultural, forestry and fishery workers" (which dominate this industry) are least intensive in routine tasks. The industries with the next lowest exposures are those with high inter-personal content of tasks (such as interaction and flexibility) which are also not easily automated. These include the accommodation, health services and retail industries.

Figure 2. Distribution of Routine Exposure Across Industries

Panel A: Initial Exposure (1990-2000)

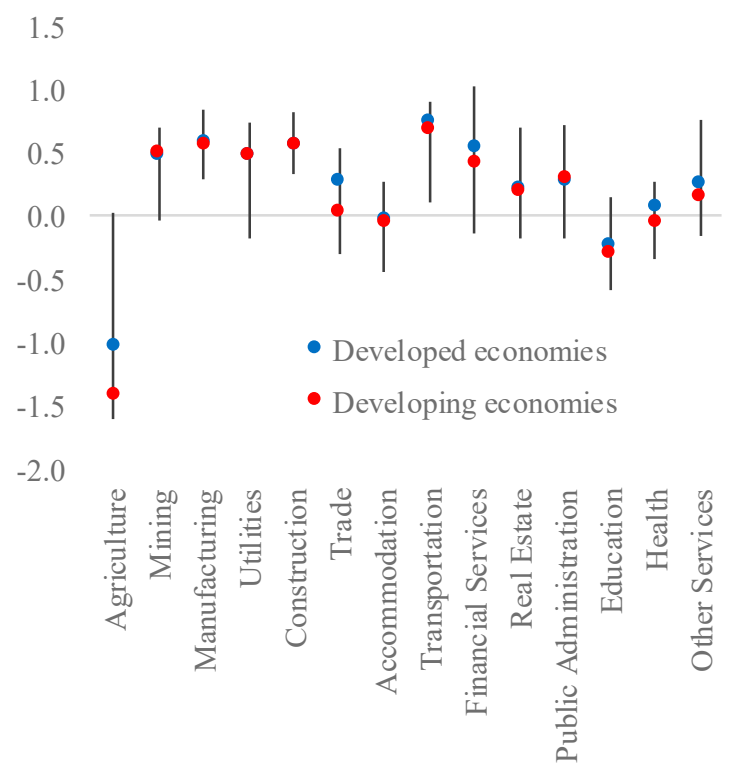

Panel B: Subsequent Exposure (2010-15)

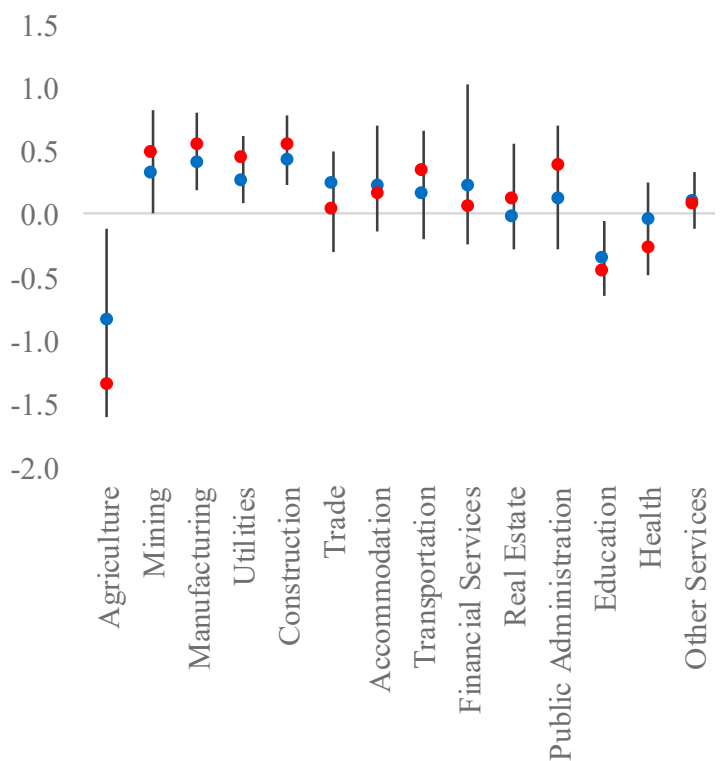

Source: Autor and Dorn (2013), databases listed in footnote 8, and authors' calculations. Note: Average routine exposure for each industry are shown by red dots (developed) and blue dots (developing).

Routine exposures are highest in industries where core tasks follow "precise, wellunderstood procedures" (Autor and Acemoglu 2011), such as manufacturing, financial services, and transportation and storage. This reflects that these industries have traditionally had high concentrations of occupations with high routine scores. For example, machine operators are pervasive in manufacturing; financial services have historically drawn on clerical workers (e.g. for data entry and accounting); and transportation and storage employs both elementary workers for manual labor, as well as clerical workers for logistics and communications. 
A striking finding is a systematic evolution of the exposures over time. In Panel A, average routine exposures are higher in developed than in developing economies in every industry, indicating that as of the early 1990s, labor in developed economies was on average more at risk of being substituted by ICT. ${ }^{12}$

Over the next two decades, however, in about half of the industries, average exposures in developing economies had overtaken those in developed economies. Notably, these were manufacturing, mining and transportation and storage, where exposures in developed countries were previously high. This suggests that where initial exposures were high, these economies more intensely displaced labor with capital, making the marginal task less routine and thus lowering routine exposure. This evolution of routine exposures reflects precisely the polarization dynamics that have occurred in many developed economies. Further exploration indicates that there is indeed a systematic correlation between initial and subsequent exposure to routinization (see stylized fact $\mathrm{C}$ below).

\section{B. The exposure to routinization has been consistently higher in developed than in} developing economies, but they have converged across these country groups over time.

An interesting fact about the exposures to routinization is revealed in Figure 3, which shows the average routine exposures of the world, developed economies and developing economies. For illustration, these are shown in the time periods 1990-95, 2000-05, and 201015.

First, average exposures are lower in developing than in developed economies in all time periods shown. As implied above, this reflects to a significant degree the higher employment by developing economies in the agriculture, fishing and forestry, where occupations have low routine task-intensity. The average exposures are not driven by a few countries, ${ }^{13}$ as exposures are uniformly lower in developing economies (though with significant heterogeneity) than in developed economies; see Figure 3B.

\footnotetext{
12 The large difference between developed and developing economies in routine exposure of the agriculture, fishing and forestry industry reflects that employment in this sector varies significantly between these economies, being much higher in developing economies than in their developed counterparts.

${ }^{13}$ Shown in Figure 3 are weighted averages, with weights given by individual country GDP in the group GDP.
} 
Second, while exposures in developing economies have risen over time, they have declined steadily in developed economies. The result is a convergence in world-wide routine exposures, from above for developed economies and from below for developing economies. An implication is that if these trends continue, developing economies will become increasingly exposed to automation of jobs, with rising risks for the hollowing-out of middleskilled labor.

\section{Figure 3. Evolution of Routine Exposure Across Country Groups}

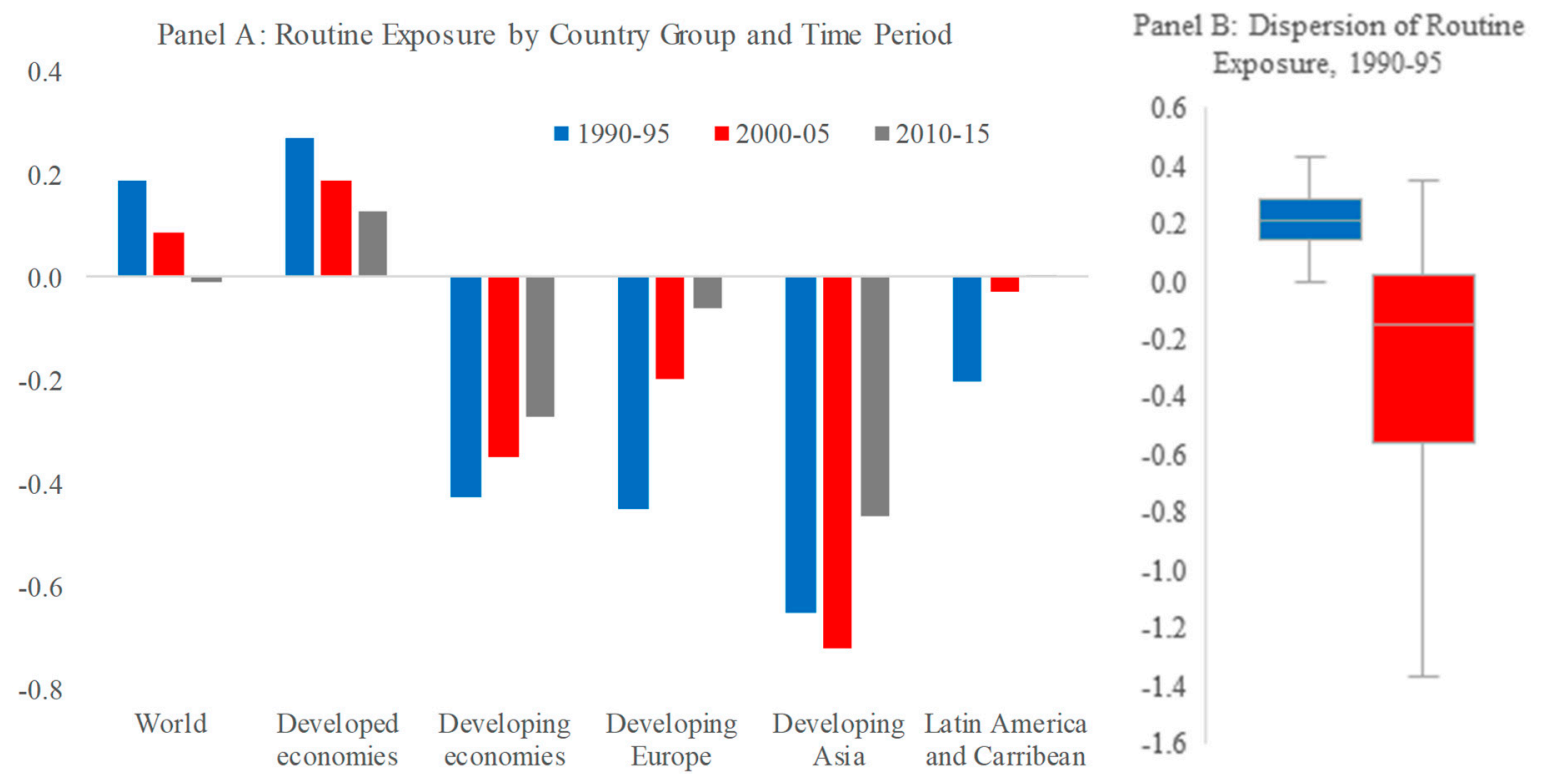

Source: Autor and Dorn (2013), databases listed in footnote 8, and authors' calculations.

What forces could affect a systematic evolution by stage of development? In developing economies, the natural transition of industry from agriculture toward manufacturing and services - structural transformation - is an explanation consistent with the sectoral employment shifts that raise exposure to routinization. As discussed in the next section, trade globalization may have also played a role by offshoring routine-intensive occupations to developing economies (Blinder and Krueger 2013). By contrast, the adoption of labor-saving technologies in developing economies, would have lowered their exposure to routinization, suggesting that their effects are either absent or offset fully by structural transformation and globalization. In developed economies, these trends have been studied extensively, and the falling routine exposures are consistent with the large-scale automation of labor performing routine tasks. 


\section{The initial exposure to routinization is a powerful predictor of the subsequent exposure to routinization.}

One important fact we uncover about the information content of the exposure to routinization is shown in Figure 4, which presents the initial exposure to routinization on the horizontal scale and the subsequent exposure on the vertical scale. It illustrates a striking negative relation between the two. There is, however, an important and subtle difference between developed economies (shown in blue) and developing economies (in red), which may differentiate how labor markets evolve in the future. ${ }^{14}$

While developed economies fall almost entirely in the fourth quadrant of Figure 4, developing economies are predominantly in the second. For developed economies, the interpretation is straightforward: the higher was initial exposure to routinization, the lower was subsequent exposure. It is consistent with the notion that where the routine-intensity of jobs was high to start with, firms more intensively displaced labor with information technology, making the marginal task less routine. Thus, in developed economies initial exposure appears to be a strong predictor of polarization.

In developing economies, the interpretation is that the higher was the initial exposure to routinization, the less is the subsequent rise in exposure. This indicates that forces that may have ordinarily lowered the exposure to routinization - such as the declining relative price of investment, or lower import substitution resulting from the erosion of comparative advantage in manufacturing (Rodrik, 2016) —were weaker than those which raised exposures, such as structural transformation, which moved labor from the least routine agrarian occupations towards manufacturing and service jobs more intensive in routine tasks.

An implication is that while the initial exposure to routinization contains important signals about the long-run exposure to routinization (equivalently, shifts in employment structure), this signal differs fundamentally between developed and developing economies. Indeed, the change in exposure is systematically related to stage of development: negatively for developed economies and positive for developing economies; Figure 4 Panel B. These changes have occurred amid deep structural changes, including the globalization of trade,

${ }^{14}$ Initial and subsequent exposures are as described in Figure 2. 
shifts in the skill supply of labor, and technological advancements, which may have impacted countries at different stages of economic development differentially. We explore this further in the empirical analysis in Section IV.

Figure 4. Initial Routine Exposure, Income Levels, and Subsequent Exposure

Panel A: Initial Routine Exposure and Subsequent Change in Routine Exposure

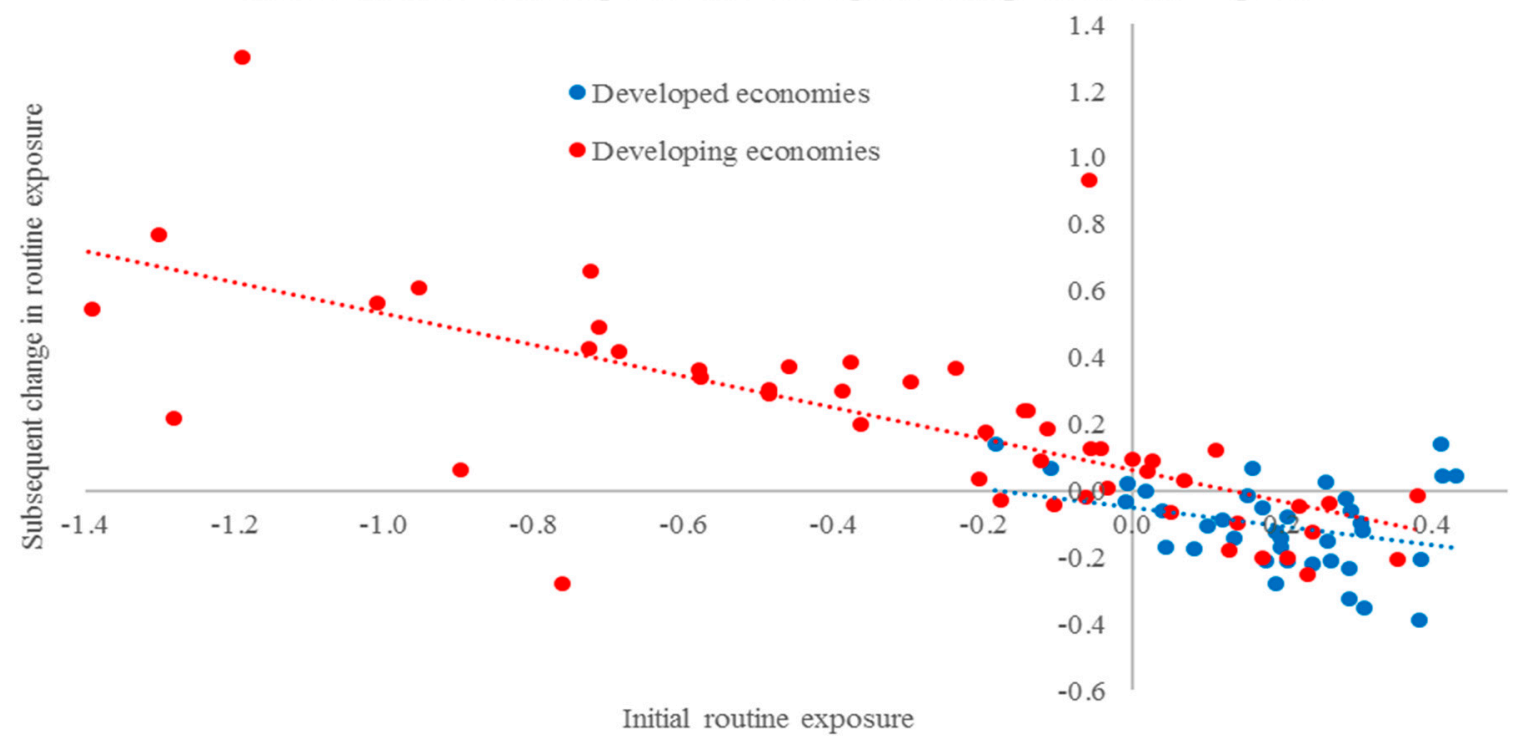

Panel B: Income Level and the Change in Routine Exposures

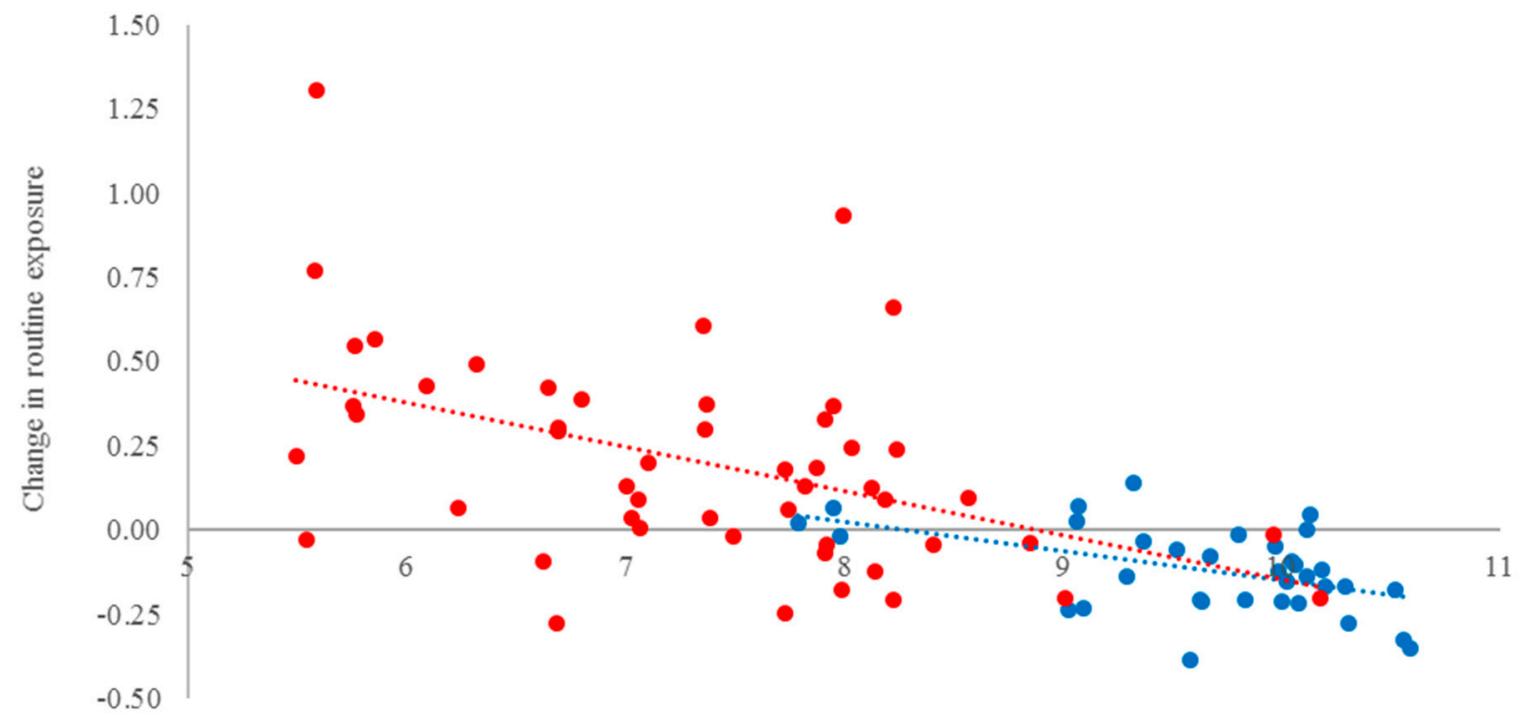

In(initial per capita GDP in US dollar)

Source: WEO, Autor and Dorn (2013), databases listed in footnote 8, and authors' calculations. 


\section{Polarization In Developed AND DeVeloping Economies: DRIVERS AND MeChANISMS}

Before turning to an empirical study of the role of routine exposures in polarization, we discuss the key drivers and mechanisms by which routinization could result in the polarization. The literature has emphasized drivers in advanced economies, as this is where the evidence of polarization lies. Such drivers may operate differently in developing economies, however, reflecting differences in the factor shares of capital and labor in production, price distortions, informational asymmetries and their relatively low stage of development. For these reasons, they may not even be operative (Maloney and Molina 2016). We discuss four inter-related factors that are relevant.

The first and most significant factor is that the advancement of technology-reflected in the rapid improvement in its productivity as well as the steep decline in the cost of computerizing routine tasks - has presented firms incentives to displace routine labor by capital (see e.g. Levy and Murnane 1996; Card and DiNardo 2006; Autor and Dorn 2013; Beaudry et. al. 2016). The hypothesis is that, all else equal, in countries where the relative price of investment goods has declined more, labor markets will have polarized more sharply (Autor, Levy and Murnane 2003).

Second, for routinization to result in polarization, a significant share of the economy must be engaged in routine occupations. That is, the routine exposure must be large enough so that a shock, such as a rapid decline in the costs of automation, can trigger measurable dislocations of labor in routine occupations. Furthermore, it must be the case that routine and nonroutine tasks are imperfectly substitutable, so that the decline in the costs of automating routine tasks does not eliminate with it the demand for nonroutine tasks (Autor et. al. 2003). The implication is that for a given decline in the relative price of investment goods, the higher the exposure to routinization, the larger the adoption of labor-saving technologies and the more severe the polarization.

Another factor, emphasized for example in Feenstra and Hanson (1996) and Acemoglu and Autor (2011) is the skill bias of ICT ( i.e., its complementarity with skilled 
labor, but substitutability or neutrality with less-skilled labor). ${ }^{15}$ The adoption of these technologies over decades has raised with it the demand for skilled labor, leading to a steady rise in their employment shares; by simultaneously displacing middle-skilled labor performing routine tasks into lower-paying service sector jobs, it has also raised the employment shares at the bottom of the distribution, thus polarizing labor markets. ${ }^{16}$

The last driver lies at the intersection of trade and technology. Several authors have argued that technological advances have not just made the automation of routine tasks more feasible, but by drastically lowering costs of offshoring tasks to locations with lower factor costs, spurred vertically-integrated production (Blinder and Krueger 2013). Blinder (2007) notes that tasks most likely to be offshored are like to be low-skilled clerical or factory jobs which require neither face-to-face interaction with customers or suppliers, nor physical proximity to specific sites. Many of these characteristics, as noted in Autor and Dorn (2013), are also defining features of routine tasks. ${ }^{17}$ This suggests that automation and offshoring may be mutually reinforcing, together lowering the relative demand for routine labor and contributing to polarization.

We consider how these arguments apply to developing economies.

\section{A. Relative price of investment goods}

The sharp decline in the relative price of investment goods is predominantly a developed economy phenomenon, as in many developing economies it has either been either stable or risen since 1990 (Dao et al 2017). Figure 5, panel A illustrates the difference in evolutions: whereas the relative price of investment declined by about 15 percent in

\footnotetext{
${ }^{15}$ The skill bias of ICT has been proposed as a key explanation for the rising wage premium of skilled workers (Feenstra 2007). Feenstra argues that as routine are automated or offshored, the composition of remaining production in developed economies has become more skill-intensive, raising the demand for high-skilled workers and generating a skilled wage premium. The growth of low-skill labor and the "twisting" of the wage distribution has led to the additional observation that the skill bias of ICT lies behind labor market polarization.

${ }^{16}$ Empirical evidence is presented in, among others, Katz and Murphy 1992; Autor et. al. 2006; Firpo, Fortin and Lemieux 2011; Autor and Dorn 2013.

${ }^{17}$ In contrast, non-routine low-skilled tasks like construction and babysitting require either physical proximity or face to face interaction, which make them unsuitable for offshoring.
} 
developed economies since 1990, in developing countries they have risen 13 percent, albeit with significant cross-country heterogeneity (panel B). ${ }^{18}$

\section{Figure 5. Relative Price of Investment Goods in Developed and Developing Economies}

Panel A: Evolution of Relative Price of Investment (1990-2015)

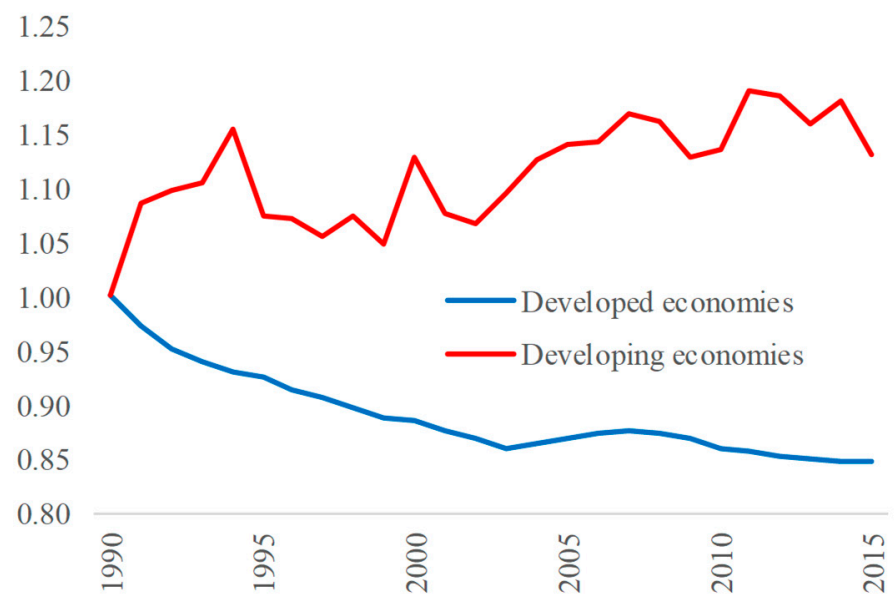

Panel B: Dispersion of Changes in

Relative Price of Investment (1990-

2015)

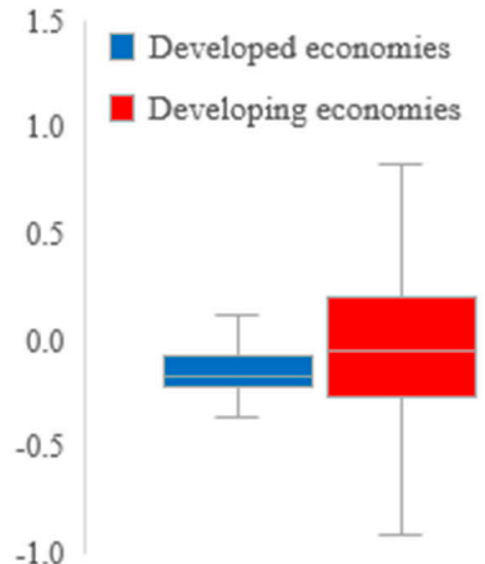

Source: Dao et. al. (2017)

To the extent that the decline in the relative price of investment goods is a key factor in the displacement of labor in developed economies, its impact on jobs in developing economies is likely to be absent or weak.

\section{B. Occupational distribution of employment}

Even faced with stable or rising capital goods prices, firms in developing economies could adopt labor-saving technologies if resulting efficiency gains outweighed higher factor costs, reflected in measurable job dislocations. For this to occur, however, a nontrivial share of existing tasks in developing economies would need to be automatable by information technologies.

\footnotetext{
${ }^{18}$ This is distinct from the stylized finding that price level of investment goods is higher in developing economies (Hsieh and Klenow 2003). The factors behind this differential evolution may be related to the high dependence on capital imports in developing countries, whose local currency prices are subject to import tariffs; the commodity-intensity of imports, non-trade barriers and transportation costs and the volatility of exchange rates (Dao et. al. 2017).
} 
It is widely held, however, that labor in developing economies is concentrated in jobs with low susceptibility to automation; ILO (2014) and Maloney and Molina (2016). The ILO estimates that about 40 percent of their workforce is employed in the primary sector. This is confirmed by the relatively low exposures to routinization of these economies, driven by the high share of their workforce in low routine-intensive agricultural occupations, and low shares in high routine-intensive occupations such as clerical workers (Figures 1 and 2). The stark differences in the occupational structure of employment between developed and developing economies is shown in Figure 6, which maps employment shares to routinization scores.

Figure 6. Routine Scores of 1-Digit Occupations and Employment Shares

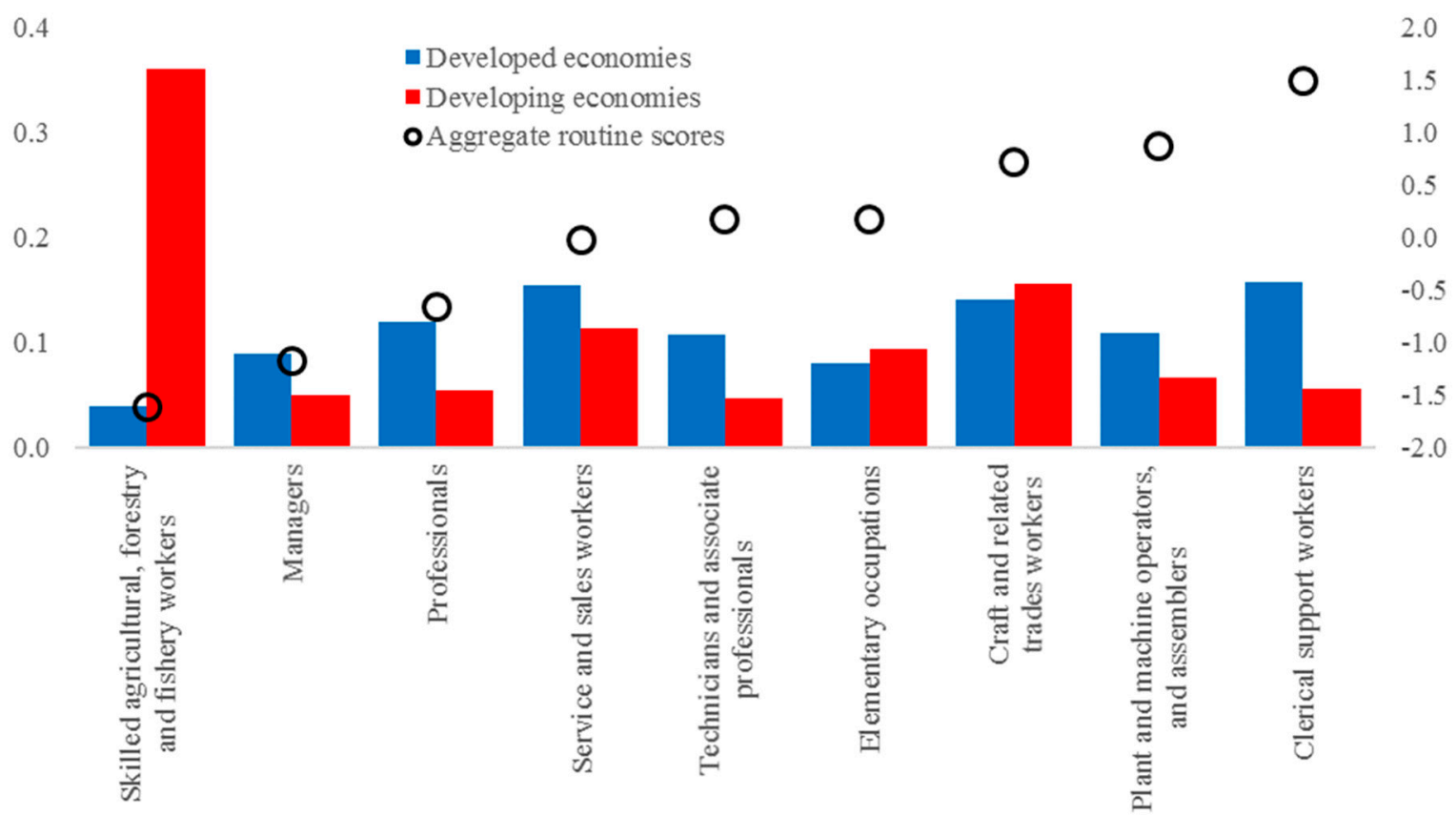

Source: IPUMS, EULFS, United Nations, ILO, national authorities, Autor and Dorn (2013)

The low share of routinizable jobs suggests that even a favorable shock to capital goods prices is unlikely to result in observable displacement at least in the near term (see also Das and Hilgenstock 2018).

\section{Globalization and the Offshoring of Tasks}

If developing economies are recipients of low-skilled jobs offshored from developed countries and such jobs have high routine-intensity as suggested by Blinder (2009), this 
implies that by raising the demand for routine labor, offshoring will offset polarization forces in developing economies. By the same logic, the offshoring of routine-intensive jobs from developed countries will lower the demand for routine labor, leading to a hollowing out in the same way as a decline in the relative price of investment goods. Autor and Dorn (2013) acknowledge that the polarization of the Unites States labor market could results from offshoring in addition (or in place of) the automation of routine jobs.

Using a measure of participation into global value chains from Koopmans, Wang and Wei (2014), ${ }^{19}$ Figure 7 suggests that the globalization of trade could have played a role in both the rising routine exposures in developing economies and the declining exposures in developed countries. We test this hypothesis more rigorously in the empirical analysis.

\section{Figure 7. Global Value Chain Participation and Change in Routine Exposure}

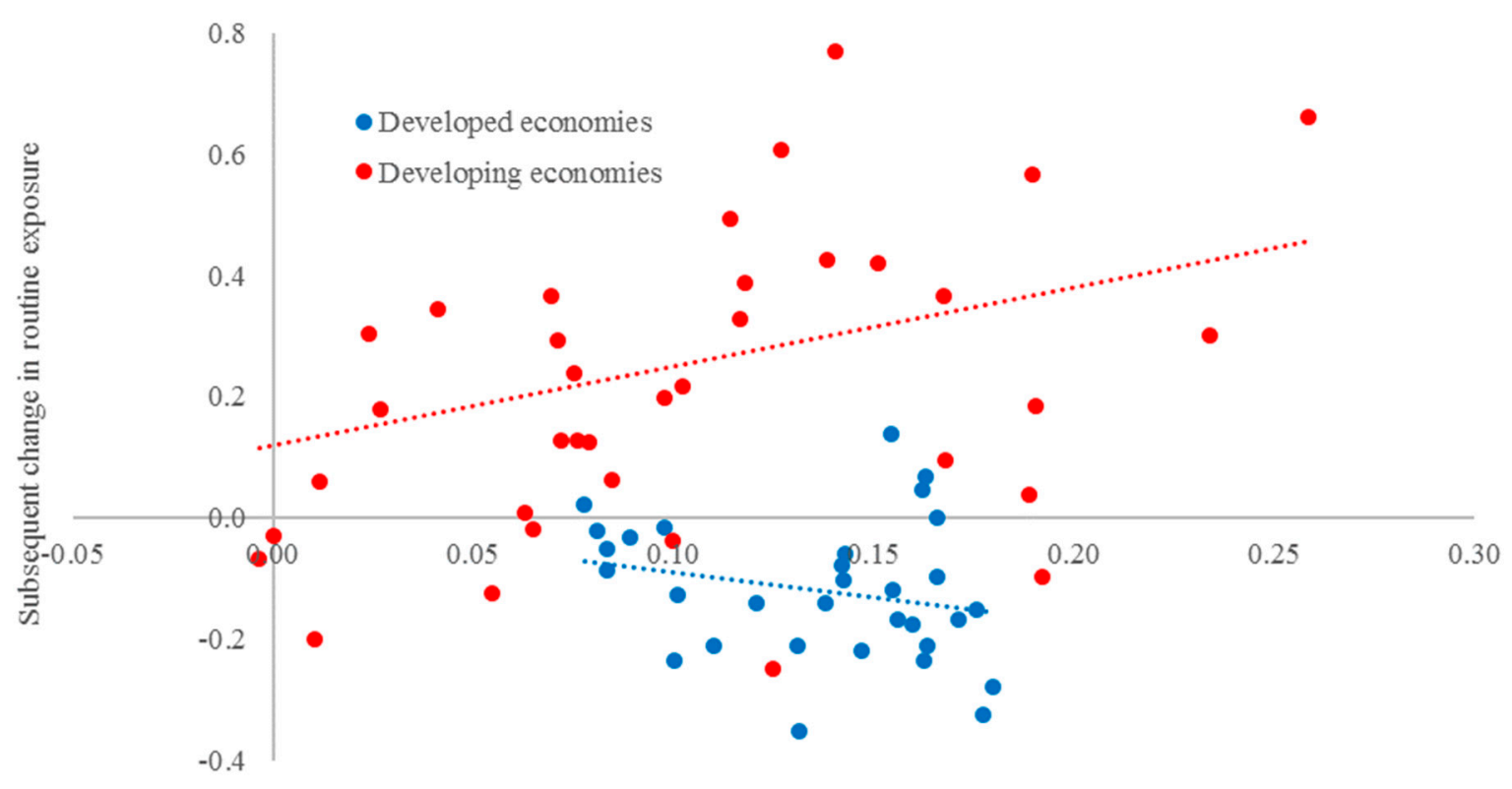

Change in global value chain participation

Source: Dao et. al. (2017), Autor and Dorn (2013), databases listed in footnote 8, and authors' calculations.

19 This is a widely-used measure to capture value-added trade, which includes measures of both backward linkages (defined as the share of foreign value added in gross exports, which captures the extent of offshoring of intermediate inputs used in exports) and forward linkages (which is defined as the share of exports consisting of intermediate inputs used by trading partners for production of their exports to third countries, and is a measure the extent of vertical specialization). See Koopmans, Wang, and Wei 2014; IMF (2016) and Dao et. al. (2017). 
Finally, the adoption of modern technologies in developing economies may be constrained by idiosyncratic factors. Comin and Mestieri (2013) find that adoption lags have converged rapidly with those in developed economies in the last few decade, but penetration rates have diverged substantially in that time. Insufficient information about new technologies and their benefits, viewed as a key determinant of adoption, is one obstacle cited as a cause of lower penetration (Foster and Rosenzweig 1995). Institutional barriers related to ineffective property rights enforcements, misappropriation of funds and lack of enforcement, are structural impediments that dissuade large-scale technological adoption. The lack of information, coupled with a limited number of suppliers of new technology, can lead to significant price dispersion a la Stigler, where end-users face significantly higher prices than those at the port, which makes the adoption of technologies less likely on the margin.

\section{EMPIRICAL EVIDENCE}

This section analyzes the robustness of the stylized findings in regression analysis. We begin with the long-run change in routine exposures (Figure 4), and assess the roles of the long-run changes in the relative price of investment goods, participation in global value chains (GVC), and structural transformation. Following Acemoglu and Restrepo (2017), we estimate a long-change regression model:

$$
\begin{aligned}
\Delta R T I_{i}= & \alpha+\beta_{1} \Delta P I_{i}+\beta_{2} S T_{i}+\beta_{3} \Delta \text { Trade }_{i}+\beta_{4} \text { Skill }_{i}+\beta_{5} \Delta P I_{i} \times D E_{i} \\
& +\beta_{6} S T_{i} \times D E_{i}+\beta_{7} \Delta \text { Trade }_{i} \times D E_{i}+\beta_{8} \text { Skill }_{i} \times D E_{i}+\varepsilon_{i}
\end{aligned}
$$

where $\Delta$ denotes the change between 1990 and 2015,PI is the relative price of investment goods, $S T$ abbreviates structural transformation, and Skill is the initial middleskill share of employment, to control the heterogeneity in labor force composition. ${ }^{20}$ Given our intention to capture the rise in vertically integrated trade, we use the measure of

\footnotetext{
${ }^{20}$ Countries with a lower relative share of medium-skill labor, all else equal, are less able to displace mediumskill labor into lower-skilled jobs. This variable is related but distinct from the initial routine exposure, since not all medium-skilled labor performs routine tasks and not all routine tasks are performed by middle-skilled labor.
} 
participation in GVC from Koopmans et. al. (2014) for Trade. Summary statistics are in Table 1.

Table 1. Summary Statistics

\begin{tabular}{|c|c|c|c|c|c|}
\hline & Min. & Max. & Mean & Median & St. Dev. \\
\hline \multicolumn{6}{|l|}{ Developed Economies } \\
\hline Change in routine exposure & -0.39 & 0.14 & -0.11 & -0.11 & 0.13 \\
\hline Change in relative price of investment & -0.74 & 0.12 & -0.17 & -0.17 & 0.17 \\
\hline Initial middle-skill employment share & 0.22 & 0.50 & 0.39 & 0.41 & 0.06 \\
\hline Structural transformation & -1.95 & 0.20 & -0.77 & -0.70 & 0.41 \\
\hline Change in global value chain participation & -0.09 & 0.42 & 0.13 & 0.14 & 0.08 \\
\hline Change in offshoring exposure & -0.31 & 0.44 & -0.08 & -0.11 & 0.15 \\
\hline \multicolumn{6}{|l|}{ Developing Economies } \\
\hline Change in routine exposure & -0.28 & 1.30 & 0.20 & 0.13 & 0.31 \\
\hline Change in relative price of investment & -1.31 & 11.03 & 0.09 & -0.05 & 1.14 \\
\hline Initial middle-skill employment share & 0.03 & 0.76 & 0.25 & 0.28 & 0.13 \\
\hline Structural transformation & -2.42 & 1.20 & -0.57 & -0.56 & 0.58 \\
\hline Change in global value chain participation & -0.34 & 7.73 & 0.17 & 0.11 & 0.67 \\
\hline Change in offshoring exposure & -0.58 & 0.61 & 0.05 & 0.05 & 0.24 \\
\hline
\end{tabular}

For structural transformation, we take the ratio of agriculture value-added to the sum of manufacturing and services value-added, and define $S T$ as the difference of this ratio between 2015 and 1990. Given the large relocation of economic activity from agriculture into other sectors in this period, $S T$ is negative for developing economies. In developed economies, such relocation began several decades ago, while the recent transition has been from manufacturing to services, reflected in the significantly smaller values of $S T .^{21}$

All variables are interacted with an indicator for developing economies, $D E$, to allow a differential impact in developed versus developing economies. Thus, estimates of $\beta_{1}, \beta_{2}, \beta_{3}$ and $\beta_{4}$ are impacts in developed economies, whereas for developing economies inference is drawn from Wald tests on the estimated sums of $\left(\beta_{1}+\beta_{5}\right),\left(\beta_{2}+\beta_{6}\right),\left(\beta_{3}+\beta_{7}\right)$ and $\left(\beta_{4}+\beta_{8}\right)$.

\footnotetext{
${ }^{21}$ We have estimated with an alternative definition, measuring structural transformation as the ratio of the value added of agriculture and manufacturing to the value added of services. These different measures result in altering the estimated coefficients, but the qualitative implications are not different from those with the original measure.
} 
Table 2 presents results for blocks of variables, as well as the full model. The main results are given in Column (10). Auxiliary results replacing Trade with a measure of the change in exposure to offshoring in column (11) are shown for comparison.

Structural transformation in developing economies is, however, robustly associated with a change in their exposures to routinization. Consistent with the definition of $S T$, as labor has moved from jobs in agriculture to sectors with higher routine-intensity (lowering the value of $S T$ ), the impact has been to raise exposures in these countries. For the median developing economy, a one standard deviation decrease of $S T$ is associated with a 0.4 increase in routine exposure. Structural transformation also affects the change in routine exposure for developed nations, as hypothesized by Baranyi and Siegel (2018). However, in the time period analyzed, the estimated impact is economically fairly small, where a one standard deviation decline in $S T$ for the median developed economy results in lowering routine exposure by .005 (about 5 percent of the standard deviation of change in exposures).

Trade has strongly affected the evolution of routine exposures in both developed and developed economies, but in opposite directions. Consistent with Blinder's hypothesis, we estimate a negative relation between rising engagement in global value gains and exposure to routinization in developed countries, and a positive relation for developing economies. In the median developed economy, an increase in Trade is associated a decline in the exposure to routinization by about 0.13 , whereas in the median developing economy, where Trade rose by 0.10 , the exposure to routinization increased by about 0.11 .

To summarize, in developed economies technological advancement along with the rising ability to move jobs offshore are the proximate causes of the decline in routine exposures over the last quarter century, while structural transformation has played a small role. In developing economies, the rise in the exposure to routinization has been driven by structural transformation and trade, which have expanded employment in sectors with higher routine-intensity. For developed countries, our results are consistent with the large body of work regarding polarization, and for developing economies we present new facts about the change in exposures and the factors behind them. 
Table 2. Determinants of Long-Run Changes in Routine Exposure

\begin{tabular}{|c|c|c|c|c|c|c|c|c|c|c|c|}
\hline VARIABLES & $(1)$ & $(2)$ & (3) & (4) & $(5)$ & $(6)$ & $(7)$ & $(8)$ & (9) & $(10)$ & (11) \\
\hline \multirow{2}{*}{$\begin{array}{l}\text { Change in relative price of } \\
\text { investment }\end{array}$} & $2.397^{* * *}$ & & & & & $0.624 * *$ & $0.650 * * *$ & & $0.523 * *$ & $0.425^{*}$ & $0.562 * *$ \\
\hline & $(0.250)$ & & & & & $(0.273)$ & $(0.233)$ & & $(0.250)$ & $(0.243)$ & $(0.227)$ \\
\hline \multirow{2}{*}{$\begin{array}{l}\text { Change in relative price of } \\
\text { investment * EM dummy }\end{array}$} & $-2.552^{* * *}$ & & & & & $-0.748 * * *$ & $-0.695^{* * *}$ & & $-0.581 * *$ & $-0.495^{* *}$ & $-0.616^{* * *}$ \\
\hline & $(0.265)$ & & & & & $(0.276)$ & $(0.246)$ & & $(0.255)$ & $(0.247)$ & $(0.231)$ \\
\hline \multirow{2}{*}{$\begin{array}{l}\text { Initial middle skill employment } \\
\text { share }\end{array}$} & & $-2.040 * * *$ & & & & $-1.749 * * *$ & & $-0.981 * * *$ & $-0.780 * * *$ & -0.0323 & -0.382 \\
\hline & & $(0.170)$ & & & & $(0.189)$ & & $(0.255)$ & $(0.268)$ & $(0.370)$ & $(0.282)$ \\
\hline \multirow{2}{*}{$\begin{array}{l}\text { Initial middle skill employment } \\
\text { share * EM dummy }\end{array}$} & & $0.553 * * *$ & & & & $0.448^{* *}$ & & 0.189 & 0.109 & $-0.744 * *$ & 0.237 \\
\hline & & $(0.147)$ & & & & $(0.186)$ & & $(0.166)$ & $(0.197)$ & $(0.356)$ & $(0.208)$ \\
\hline \multirow[t]{2}{*}{ Structural transformation } & & & -0.0215 & & & & -0.0475 & -0.0569 & -0.0605 & $-0.147^{* *}$ & -0.0583 \\
\hline & & & $(0.0542)$ & & & & $(0.0527)$ & $(0.0542)$ & $(0.0528)$ & $(0.0596)$ & $(0.0474)$ \\
\hline \multirow{2}{*}{$\begin{array}{l}\text { Structural transformation } \\
\text { *EM dummy }\end{array}$} & & & $-0.557^{* * *}$ & & & & $-0.463^{* * *}$ & $-0.313^{* * *}$ & $-0.297 * * *$ & $-0.165^{*}$ & $-0.187^{* *}$ \\
\hline & & & $(0.0449)$ & & & & $(0.0567)$ & $(0.0825)$ & $(0.0852)$ & $(0.0976)$ & $(0.0843)$ \\
\hline \multirow{2}{*}{$\begin{array}{l}\text { Change in global value chain } \\
\text { participation }\end{array}$} & & & & $-1.519 * * *$ & & & & & & $-2.688 * * *$ & \\
\hline & & & & $(0.544)$ & & & & & & $(0.985)$ & \\
\hline \multirow{2}{*}{$\begin{array}{l}\text { Change in global value chain } \\
\text { participation * EM dummy }\end{array}$} & & & & $3.184 * * *$ & & & & & & $2.932 * * *$ & \\
\hline & & & & $(0.258)$ & & & & & & $(1.052)$ & \\
\hline \multirow[t]{2}{*}{ Change in offshoring exposure } & & & & & $1.472 * * *$ & & & & & & 0.374 \\
\hline & & & & & $(0.219)$ & & & & & & $(0.233)$ \\
\hline \multirow{2}{*}{$\begin{array}{l}\text { Change in offshoring exposure } \\
\text { * EM dummy }\end{array}$} & & & & & 0.0989 & & & & & & 0.354 \\
\hline & & & & & $(0.314)$ & & & & & & $(0.284)$ \\
\hline \multirow[t]{2}{*}{ Constant } & $0.286^{* * *}$ & $0.719 * * *$ & $-0.142 * * *$ & 0.0841 & $0.0877 * * *$ & $0.692 * * *$ & -0.0609 & $0.242 * *$ & $0.236^{* *}$ & $0.262^{* *}$ & 0.121 \\
\hline & $(0.0344)$ & $(0.0690)$ & $(0.0310)$ & $(0.0791)$ & $(0.0274)$ & $(0.0687)$ & $(0.0420)$ & $(0.106)$ & $(0.110)$ & $(0.116)$ & $(0.103)$ \\
\hline Observations & 85 & 89 & 82 & 87 & 89 & 85 & 78 & 82 & 78 & 78 & 78 \\
\hline R-squared & 0.533 & 0.755 & 0.789 & 0.675 & 0.706 & 0.790 & 0.827 & 0.823 & 0.846 & 0.862 & 0.880 \\
\hline
\end{tabular}


We next turn to a question generated by the stylized findings: conditional on other factors that shift employment shares, does the initial exposure to routinization have predictive power for subsequent changes in occupational employment shares? Establishing that a current and measurable indicator of the labor market contains information about future shifts in employment provides valuable information in anticipating future developments in labor markets, including polarization and wage dynamics.

Table 3. Initial Routine Exposure and Changes in Occupational Employment Shares

\begin{tabular}{|c|c|c|c|c|c|}
\hline & Min. & Max. & Mean & Median & Std. Dev. \\
\hline \multicolumn{6}{|l|}{ Developed Economies } \\
\hline Initial routine exposure & -0.18 & 0.43 & 0.20 & 0.20 & 0.14 \\
\hline \multicolumn{6}{|l|}{ Change in Employment Shares of: } \\
\hline Managers & -0.18 & 0.08 & -0.01 & 0.00 & 0.04 \\
\hline Professionals & 0.01 & 0.27 & 0.11 & 0.10 & 0.06 \\
\hline Associate professionals & -0.11 & 0.12 & 0.03 & 0.03 & 0.05 \\
\hline Clerical workers & -0.18 & 0.16 & -0.02 & -0.03 & 0.05 \\
\hline Service and sales workers & -0.18 & 0.17 & 0.03 & 0.03 & 0.06 \\
\hline Skilled agric., forestry, and fishery work. & -0.12 & 0.00 & -0.03 & -0.02 & 0.03 \\
\hline Craft and related trades workers & -0.22 & 0.03 & -0.06 & -0.06 & 0.05 \\
\hline Machine and plant operators & -0.22 & 0.11 & -0.04 & -0.03 & 0.05 \\
\hline Elementary occupations & -0.11 & 0.09 & -0.02 & -0.02 & 0.04 \\
\hline \multicolumn{6}{|l|}{ Developing Economies } \\
\hline Initial routine exposure & -1.46 & 0.38 & -0.34 & -0.20 & 0.51 \\
\hline \multicolumn{6}{|l|}{ Change in Employment Shares of: } \\
\hline Managers & -0.10 & 0.12 & 0.01 & 0.0 & 0.04 \\
\hline Professionals & -0.11 & 0.21 & 0.04 & 0.03 & 0.05 \\
\hline Associate professionals & -0.15 & 0.17 & 0.02 & 0.02 & 0.06 \\
\hline Clerical workers & -0.10 & 0.13 & 0.01 & 0.00 & 0.04 \\
\hline Service and sales workers & -0.13 & 0.31 & 0.08 & 0.09 & 0.08 \\
\hline Skilled agric., forestry, and fishery work. & -1.97 & 0.44 & -0.16 & -0.11 & 0.30 \\
\hline Craft and related trades workers & -0.33 & 0.35 & -0.01 & -0.02 & 0.10 \\
\hline Machine and plant operators & -0.17 & 0.30 & 0.01 & 0.01 & 0.07 \\
\hline Elementary occupations & -0.54 & 0.91 & 0.02 & 0.02 & 0.20 \\
\hline
\end{tabular}

Notes: The change in occupational employment share is measured as the employment share in 2015 minus the employment share in 1990.

To answer this question, we analyze the change in employment shares between 2015 and 1990 for each of the nine 1-digit occupations. Covariates are the same as in Table 2 apart from middle-skilled shares, which is replaced with the initial exposure to routinization. ${ }^{22}$

\footnotetext{
${ }^{22}$ As the middle-skilled shares are by construction linear combinations of employment shares, retaining them could lead to spurious estimation.
} 
Table 3 gives summary statistics of the initial routine exposures and the changes in occupational shares.

Figure 8. Initial Routine Exposure and Changes in Occupational Employment Shares

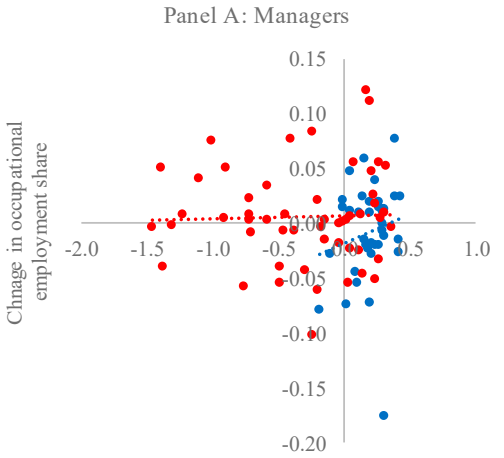

Initial routine exposure

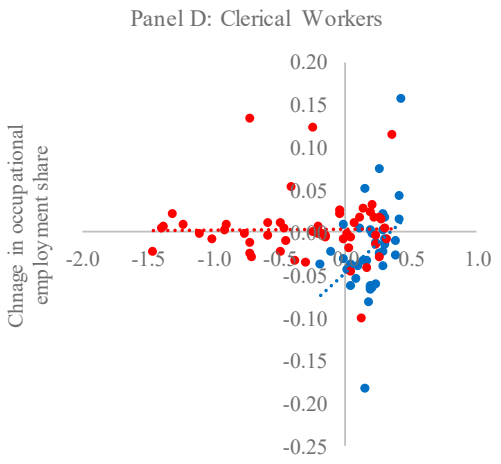

Initial routine exposure

Panel G: Craft Workers and Related Trades

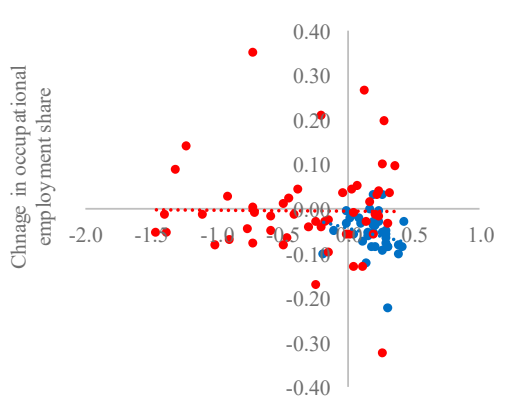

Initial routine exposure

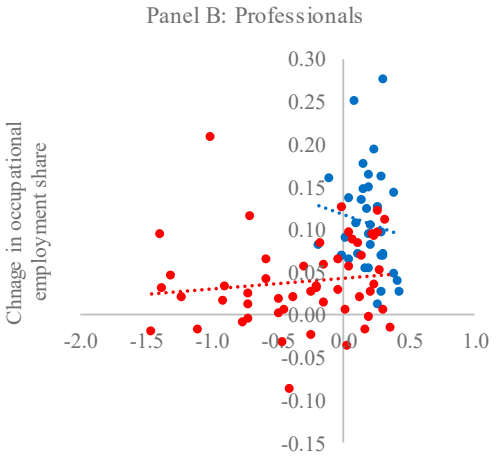

Initial routine exposure

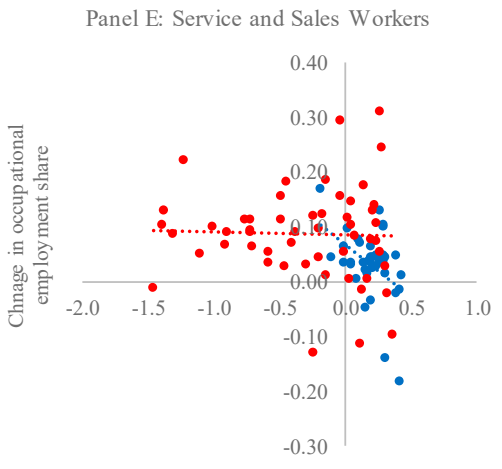

Initial routine exposure

Panel H: Machine and Plant Operators

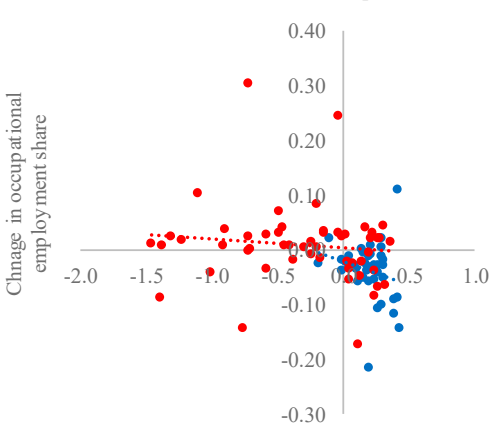

Initial routine exposure

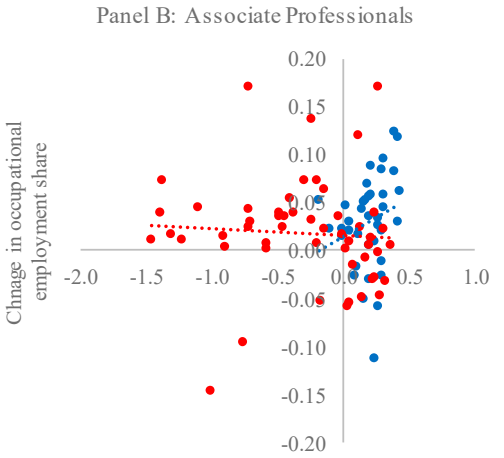

Initial routine exposure

Panel F: Skilled Agricultural, Forestry and Fishery Workers

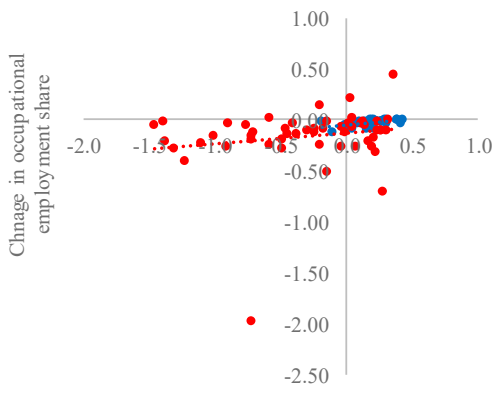

Initial routine exposure

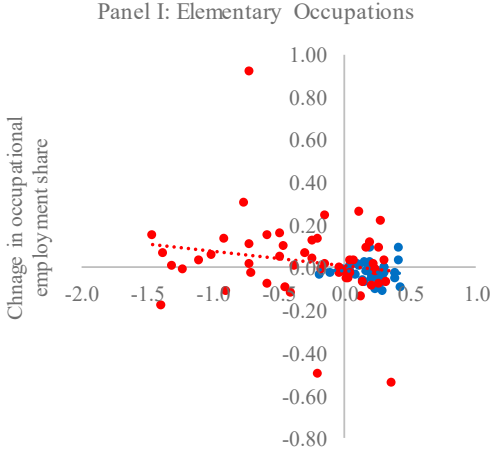

Initial routine exposure

Source: Autor and Dorn (2013), databases listed in footnote 8, and authors' calculations.

To interpret the results, note that as the dependent variable is a change, the estimated coefficients indicate whether an increase in a covariate is associated with a larger or smaller change in employment shares. Since for most occupations in developing economies, the pairs of initial routine exposure and change in employment shares fall in the second quadrant with the exception of the agricultural workers (see Figure 8), a negative coefficient on initial 
exposure means that an increase in the exposure to routinization leads to a smaller increase in employment shares. An analogous interpretation applies in developed economies, where the initial exposures and employment shares are spread more evenly between the first and fourth quadrants.

Results in Table 4 confirm that in developed economies, the initial exposure is associated with the increase in employment shares for associate professionals and clerical workers, but a decrease in employment shares of service workers, craft workers and machine operators - among the most routine-exposed occupations. An increase in the initial exposure to routinization by 0.14 (one standard deviation of the initial exposure in developed economies), is associated with respectively $2.7,1$ and 0.8 percentage point decline in the employment shares of service workers, craft workers and machine operators respectively; but a 3.5 and 4 percentage point increase, respectively, in the employment shares of associate professionals and clerical workers. ${ }^{23}$ The results are significant at the 1 percent error level for associate professionals, clerical workers, and service workers, but are less precise for craft workers and machine operators, which are statistically significant at the 12 percent error level.

For developing economies, Wald tests on the sum of the estimated impacts of initial exposure and its interaction with the developing economies indicator reveal the following: the initial exposure to routinization has a significant negative coefficient for clerical workers, service workers and machine operators. ${ }^{24}$ As the initial exposure-employment share pairs of these occupations fall largely in the second quadrant of Figure 8, an increase in the initial exposure is associated with a smaller increase in corresponding employment shares. Analogously, the positive coefficient on the initial exposure in agriculture (where the

\footnotetext{
${ }^{23}$ Although the result for clerical workers may seem inconsistent with their high average routine scores in Figure 1, it is reconciled by two facts. One is that, as noted in Section 2, there is significant diversity in "clerical occupations", many of which have lower routine scores than professionals. A second fact is that those occupations within likely reflects the fact that the significant displacement of these jobs took place in the 1980s and 1990s, before the time period which our analysis focuses on (see Autor and Dorn 2013).

${ }^{24}$ For machine operators, the coefficient estimates on the initial exposure to routinization and its interaction with the developing economy indicator are not statistically significant at conventional error levels but their sum is statistically distinguishable from zero at the 10 percent error level reflecting the negative covariance between the coefficient estimates.
} 
exposure-employment share pairs fall in the third quadrant) implies that an increase in exposure is associated with a smaller decline in agricultural employment shares.

In summary, the initial exposure to routinization is predictive of future changes in employment shares. In developed economies, higher initial exposures are associated with subsequent declines in the employment shares of routine-intensive occupations but increases in employment shares of occupations which have weak exposure to routinization. In developing economies, higher initial exposures are strongly associated with future declines in employment shares of agriculture, but large future increases in occupations with high routine-intensity, including those in services, clerical work and some professional occupations.

Finally, we consider whether the initial exposure to routinization is empirically linked to the evolution of wages. The greater the exposure to routinization, all else equal, the greater is the likelihood that labor-saving technology is adopted and the lower will be real wages as labor's bargaining power erodes.

As wage data are limited, our analysis is restricted to real wages in just the manufacturing sector of forty-eight countries. We correspondingly treat these results as illustrative. The dependent variable is the percentage change in real wages between 1990 and 2015 , using the same covariates as in the previous regression. Table $\mathrm{X}$ shows the strong predictive power of the initial exposure to routinization on real wages. In both developed and developing economies, our estimates indicate that the increase in exposure to routinization is associated with declines in real wages, consistent with expectations. The estimates suggest that a unit increase in the initial exposure to routinization is associated with a decline of 11 percent in real manufacturing wages. While not conclusive due to the small sample, our results are consistent with those in the literature (e.g. Autor and Dorn 2013; Dao et. al. 2017). 
Table 4. Determinants of Long-Run Changes in Occupational Employment Shares

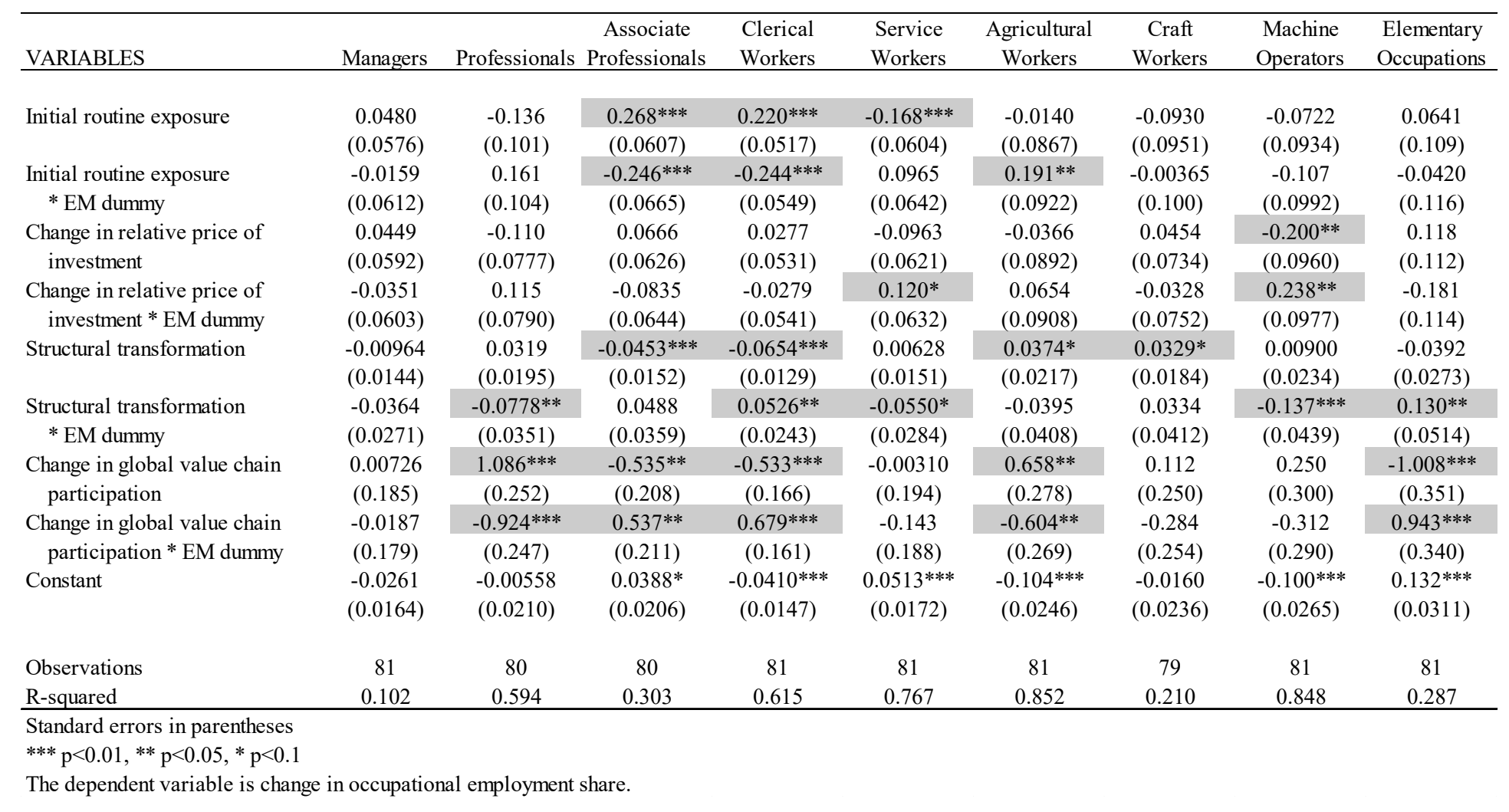




\section{Conclusions}

In this paper, we combine data on the occupational structure of employment with an index of the routine-intensity of occupations to construct a measure of the exposure to routinization, i.e., the risk of job displacement by ICT. Drawing from the evidence for over 80 countries, we begin by assembling new facts about the exposure to routinization over the last quarter century, and then analyze how they relate to labor market developments in developed and developing economies.

First, developing economies are significantly less exposed to routinization than their developed counterparts, but exposures have steadily converged between the two in the last quarter century. Second, in countries that had initially high exposure to routinization, polarization dynamics have been strong, resulting in a lower subsequent exposure. But among countries with low initial exposure, the structural transformation of their economies along with the on-shoring of routine tasks has prevailed, raising subsequent exposure to routinization.

The empirical evidence confirms that the steep decline in the relative price of investment goods is a key contributor to falling routine exposures, and thus polarization, in developed economies. But in developing economies, structural transformation and the expansion of vertically-integrated trade are "anti-polarization" forces that raise exposures.

What do these trends hold for the future of labor markets in developing economies? The historical evidence aside, automation could have sizable impacts on developing economies in the future, considering the rapid pace at which some have adopted technology in recent years, as argued by Hallward-Driemeier and Nayyar (2018); see also World Bank (2016).

What do these trends hold for the future of labor markets in developing economies? The historical evidence aside, automation could have sizable impacts on developing economies in the future, considering the rapid pace at which some have adopted technology in recent years. As argued by Hallward-Driemeier and Nayyar (2018), impacts may differ across developing economies, given that the pace of change is uneven and opportunities remain in certain sub-sectors to pursue production with existing technologies and use of lower-skilled workers. Led most prominently by China, developing economies are among the 
leaders in industrial robotization (International Federation of Robotics, 2017). Rising routine exposures in these economies implies that currently labor-intensive industries may be getting increasingly exposed to technological disruptions, with potential for significant labor displacement. The IMF notes that technological advance offers prospects for stronger productivity and growth, but brings risks of increased income polarization (IMF 2018C).

As hosts to a significant fraction of the global labor force, the consequences for developing economies could be profound. A specific concern is that technological dynamics could erode middle-skilled employment much earlier in the convergence process than it did in developed economies, bringing it with premature deindustrialization, adverse consequences for productivity and growth, and potentially derailing income convergence, as most prominently argued by Rodrik (2016). Das and Hilgenstock (2018) explore the implications of a trend rise in the relative price of labor to capital on the large emerging markets that together account for nearly 40 percent of the world's labor force. Under some assumptions about the change in factor costs, the diffusion technology and the evolution of the exposure to routinization, preliminary results suggest that polarization is not imminent, but the factors behind them are gathering force over a longer horizon of ten to twenty years.

The experience of developed countries in managing the fallout from polarization could hold important lessons for policymakers in developing economies. Increasing the supply of high-skilled labor, raising investment in technological proficiency and building safety buffers are key policy challenges ahead (see Dao et. al. 2017). In many developing countries, unprecedented rates of urbanization since the early 1990s have led to significant reductions in poverty rates and the emergence of a middle class, but a step rise in skilled wage-premia and income inequality as well (Goldberg and Pavcnik 2007). Were developing economy labor markets to polarize, income would shift further towards high-wage individuals, exacerbating these trends and raising difficult distributional issues for policymakers. 


\section{APPENDIX}

A. Exposures to Offshorability

We construct a measure of the exposure to offshorability analogous with the exposures to routinization. The "exposure to offshorability" is a measure of the extent to which jobs are at risk of being offshored. The construction of this measure, along with key stylized facts are at the online appendix: https://sites.google.com/view/exposure-to$\underline{\text { routinization/home }}$ 


\section{B. Database of Exposures to Routinization and Offshorability}

Advanced Economies

Austria

Belgium

Canada

Cyprus

Czech Republic

Denmark

Estonia

Finland

France

Germany

Hong Kong SAR

Iceland

Ireland

Israel

Italy

Japan

Korea

Latvia
Lithuania

Luxembourg

Macau

Malta

Netherlands

New Zealand

Norway

Portugal

Puerto Rico

San Marino

Singapore

Slovak Republic

Slovenia

Spain

Sweden

Switzerland

United Kingdom

United States

Developing Economies

Albania

Algeria

Antigua and Barbuda

Argentina

Armenia

Azerbaijan

Bahrain

Barbados

Belarus

Belize

Bangladesh

Bhutan

Bolivia

Bosnia and Herzegovina

Botswana

Brazil

Brunei Darussalam

Bulgaria

Burkina Faso

Cambodia

Cameroon

Chile

China

Colombia

Costa Rica

Croatia

Dominica

Dominican Republic

Ecuador

Egypt

El Salvador

Eritrea

Ethiopia

Fiji

Georgia

Ghana

Grenada

Guatemala

Table A1. Economies and Time Coverage (as of 2018)

1986, 1991, 1997-2014

1971, 1981, 1991, 1995-2015

1993-2015

$1971,1981,1987-2014$

1999-2015

1993-2015

$1992-2015$

1989-2015

1997-2015

$1962,1968,1975,1982,1990,1992-2015$

$1970,1981,1987,1992-2015$

$1971,1981,1991-2015$

1991, 1994-2014

1991-2015

1971, 1981, 1986-2015

1995-2015

1992-2015

1973-2015

1993-2015

1996-2015

1997-2015

1992-2015

1996-2015

1995, 2000-2015

1992-2015

1992-2008

1996-2015

1981, 1991-2015

1970, 1980, 1990, 1996-2008, 2010

1995-1999, 2007-2008

1985-2015

1994-2015

1993-2015

1981, 1991-2015

1997-2015

1970, 1980, 1990-2015

1991-2015

1960, 1970, 1980, 1990, 2000-2014

2001, 2009, 2011

2001, 2003-2004, 2014

2001

1970, 1980, 1998-2006, 2009-2012, 2014

2001, 2011

2003-2008

2001

1994-2004

1999, 2009

1993-1999, 2005, 2015

2010

1976, 1992-1997, 1999-2002, 2004-2007, 2012

2014-2015

1998, 2000-2001, 2003, 2006, 2010

1960, 1970, 1980, 1991, 2000, 2002-2007, 2009-2010

2001, 2011

$2000-2015$

1996

1998, 2000-2001, 2004, 2008, 2010

2005

1960, 1970, 1982, 1992, 2002, 2010-2015

$1982,1990,1995,2000,2005,2010,2015$

1964, 1973

1973, 1984, 1997-2008, 2010-2013

1996-2015

1991, 1997, 1999, 2001

1960, 1970, 1981, 1996-2007, 2009-2010, 2014

$1962,1982,1990,1999-2006,2010-2015$

1996-2007, 2011-2013, 2015

992, 1995-2010, 2012-2013

1996

1984, 1994, 1999, 2004-2006, 2009-2013

$1976,1986,1996,2007$

1998-2007

1984, 2000, 2010

1994, 1996, 1998

2011-2015

Developing Economies

Guinea

Haiti 1982, 2003

Hungary 1995-2015

India $\quad 1983,1987,1993,1999,2004,2012-2014$

Indonesia $\quad 1971,1976,1980,1985,1990,1995,2005,2007-2010,2013,2015$

Iran

Iraq

Jamaica

Jordan

Kazakhstan

Kiribati

Kuwait

Kyrgyz Republic

Laos

Lebanon

Lesotho

Liberia

Libya

Macedonia, FYR

Madagascar

Malawi

Malaysia

Maldives

Mali

Mauritius

Mexico

Moldova

Mongolia

Morocco

Mozambique

Namibia

Nepal

Nicaragua

Nigeria

Oman

Pakistan

Palau

Panama

Papua New Guinea

Paraguay

Peru

Philippines

Poland

Qatar

Romania

Russia

Rwanda

Samoa

Saudi Arabia

Senegal

Serbia

Seychelles

Sierra Leone

South Africa

South Sudan

Sri Lanka

St. Lucia

Sudan

Suriname

Swaziland

Syria

Tajikistan

Tanzania

Thailand

Timor-Leste

Tonga

Turkey

Uganda

Ukraine

United Arab Emirates

1997

1982, 1991, 2001, 2011

2004

1999, 2001-2008

2010

2005, 2011

1999, 2002-2006, 2013-2015

1995

2004, 2007

1999, 2006, 2008

1974, 2008

2006

2002-2008, 2011-2015

2005

1987, 1998, 2008

1970, 1980, 1991, 2000-2015

2006, 2008, 2010

1987, 1998, 2009

1995, 2000, 2004-2008, 2011

1960, 1970, 1990-1991, 1993, 1995-2008, 2010-2015

1999-2015

2000, 2005-2012, 2014-2015

1982, 1994, 2004-2008

1997, 2007

2000-2001, 2004

1999, 2001

1971, 1995, 2003-2006

2008-2010

1993, 1996, 2000

1973, 2001-2008

2005

1960, 1970, 1980, 1990, 2000-2012, 2014

2000

1962, 1972, 1982, 1992, 2002, 2007-2008, 2011-2015

1993, 1996-2010, 2015

1990, 2000-2011, 2014-2015

1995-2015

1997, 2001, 2004, 2006-2007, 2010, 2013

1992, 1997-2015

1997-2015

2002

1976, 2001

2014

1988

2004-2015

2010, 2015

2004

1996, 2000-2009, 2011-2012

2008

2002-2010

1991

2008

2004, 2013

1997

2007

2010

2001-2002, 2006, 2014

$1970,1980,1990,2000-2008,2010-2014$

2004

2003, 2006

$1985,1990,2000-2015$

2002-2003

$1995-2015$

$1995,2000,2005,2008$ 


\section{REFERENCES}

Acemoglu, D, and D. H. Autor. 2011. "Skill, Tasks and Technologies: Implications for Employment and Earnings.” In Handbook of Labor Economics, Volume 4. Elsevier: Amsterdam.

Autor, D. H., and D. Dorn. 2013. "The growth of low-skill service jobs and the polarization of the US labor market." American Economic Review 103 (5): 1553-1597.

Autor, D., H., Frank Levy, and R. J. Murnane. 2003. "Computer-based technological change and skill demands: Reconciling the perspectives of economists and sociologists." In Low-wage America: How employers are reshaping opportunity in the workplace. Russell Sage Foundation, New York.

Autor, D.H, L. F. Katz, and M. S. Kearney. 2006. "The Polarization of the U.S. Labor Market.” NBER Working Paper No. 11986. National Bureau of Economic Research. Cambridge.

Bárány, Z and C. Siegel. 2018. "Job polarization and structural change". American Economic Journal: Macroeconomics, 10, 57-89.

Beaudry, P., D. Green, and B. M. Sand. 2016. "The Great Reversal in the Demand for Skill and Cognitive Tasks," Journal of Labor Economics 34, no. S1 (Part 2, January 2016): S199-S247.

Blinder, A. and A. Krueger, 2013. "Alternative Measures of Offshorability: A Survey Approach," Journal of Labor Economics, University of Chicago Press, vol. 31(S1), pages S97 - S128.

Card, D and J. E. DiNardo. "Skill-Biased Technological Change and Rising Wage Inequality: Some Problems and Puzzles," Journal of Labor Economics, 2002, 20, 733-783.

Comin, D and M. Mestiere. 2013. "If Technology Has Arrived Everywhere, Why Has Income Diverged?” working paper, Harvard Business School.

Dao, M, M. Das, Z. Koczan and W. Lian. 2017. "Why is Labor Receiving a Smaller Share of Global Income? Theory and Evidence", IMF WP Series

Das, M and B. Hilgenstock. 2018. "When Cheap Labor meets Cheap Robots: the Future of labor markets in Developing Economies", mimeo, IMF.

Eden, M and P. Gaggl. 2015. "On the Welfare Implications of Automation." Policy Research Working Paper 7487. World Bank, Washington, D.C.

Feenstra, R. C. 2007. "Globalization and its Impact on Labor." Presented as the Global Economy Lecture, Vienna Institute for International Economics Studies

Feenstra, R. C., and G. H. Hanson. 1996. "The impact of outsourcing and high-technology capital on wages: estimates for the United States, 1979-1990." The Quarterly Journal of Economics 114 (3): 907-940. 
Frey, C and M. Osborne. 2017. "The Future of Employment: How Susceptible are Jobs to Computerisation". Technological Forecasting and Social Change, 114, 254-280.

Firpo, S., N. M. Fortin, and T. Lemieux. 2011. "Occupational tasks and changes in the wage structure". University of British Columbia.

Foster, A and M. Rosenzweig. 1995. "Learning by Doing and Learning from Others: Human Capital and Technical Change in Agriculture". Journal of Political Economy, 103, 1176-1209.

Goldberg, P. and N. Pavcnik. 2007. "Distributional Effects of Globalization in Developing Countries". Journal of Economic Literature, 45, 39-82.

Goos, M., and A. Manning. 2007. "Lousy and Lovely Jobs: The Rising Polarization of Work in Britain." The Review of Economics and Statistics 89 (1): 118-133.

Goos, M, A. Manning, and A. Salomons. 2014. "Explaining Job Polarization: Routine-Biased Technological Change and Offshoring." The American Economic Review 104 (8): 2509-2526.

Hallward-Driemeier, M. and G. Nayyar. 2018. "Trouble in the Making? The Future of Manufacturing-Led Development”. Washington DC: World Bank.

Herrendorf, B, C. Harrington, and A.Valentinyi. 2014. "Growth and Structural Transformation," in Philippe Aghion and Steven N. Durlauf, eds., Handbook of Economic Growth, Vol. 2, 855-941.

Hsieh, C-T and P. J. Klenow. 2007. "Relative Prices and Relative Prosperity." American Economic Review,97, 562-585.

International Labor Organization. 2014. "World of Work Report 2014: Developing with Jobs".

International Federation of Robotics, 2017. "World Robotics 2017".

International Monetary Fund. 2018A. "Labor Force Participation in Advanced Economies: Drivers and Prospects”, Chapter 3, World Economic Outlook, forthcoming April 2018.

International Monetary Fund. 2018B. "Youth Labor Market Prospects in Emerging Markets and Developing Economies: Drivers and Policies", Staff Discussion Note, forthcoming.

International Monetary Fund. 2018C. "Technology and the Future of Work”. Forthcoming.

Ikenaga, T. and Kamibayashi, R. 2016. "Task Polarization in the Japanese Labor Market: Evidence of a Long-Term Trend”. Industrial Relations, 55, 267-293.

Karabarbounis, L, and B. Neiman. 2014. "The Global Decline of the Labor Share." The Quarterly Journal of Economics 129 (1): 61-103. 
Katz, L and K. Murphy. 1992. "Changes in Relative Wages, 1963-1987: Supply and Demand Factors.” The Quarterly Journal of Economics 107 (1): 35-78.

Koopman R., Z. Wang and S. Wei. 2014. "Tracing Value-Added and Double Counting in Gross Exports”. American Economic Review, 104, 459-94.

Levy, F, and R. Murnane. 1996. "With What Skills Are Computers a Complement?" The American Economic Review, 86, 258-62.

Michael, G, A. Natraj, and J.Van Reenen. 2013. "Has ICT Polarized Skill Demand? Evidence from Eleven Countries over 25 Years.” NBER Working Paper No. 16138.

Maloney, W. and C. Molina. 2016. Are Automation and Trade Polarizing Developing Country Labor Markets, Too? Policy Research Working Paper 7922. World Bank, Washington DC.

Nordhaus, W. 2007. Two centuries of productivity growth in computing. The Journal of Economic History, 67, 128-159.

Rodrik, D. 2016. "Premature deindustrialization," Journal of Economic Growth, 21, 1, 1-33.

Reijnders, L. and de Vries, G. 2017. "Job Polarization in Advanced and Emerging Countries". University of Groningen Working Paper.

Spitz-Oener, A. 2006. "Technical Change, Job Tasks, and Rising Educational Demands: Looking outside the Wage Structure," Journal of Labor Economics 24, no. 2 (April 2006): 235-270.

World Bank. 2016. World Development Report 2016: Digital Dividends. Washington DC. 